Universidad de Lima

Facultad de Comunicación

Carrera de Comunicación

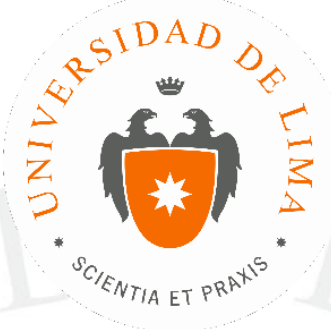

\title{
LA IMPORTANCIA DE LA COMUNICACIÓN INTERNA EN ORGANIZACIONES DEL TERCER SECTOR: CASO ENSEÑA PERÚ
}

Trabajo de Investigación para optar el Título Profesional de Licenciado en Comunicación

\section{Carolina Marcella Gutiérrez Cottle}

Código 20102831

\author{
Asesora \\ Wendy Domenack Bracamonte
}

Lima-Perú

Febrero - 2017 


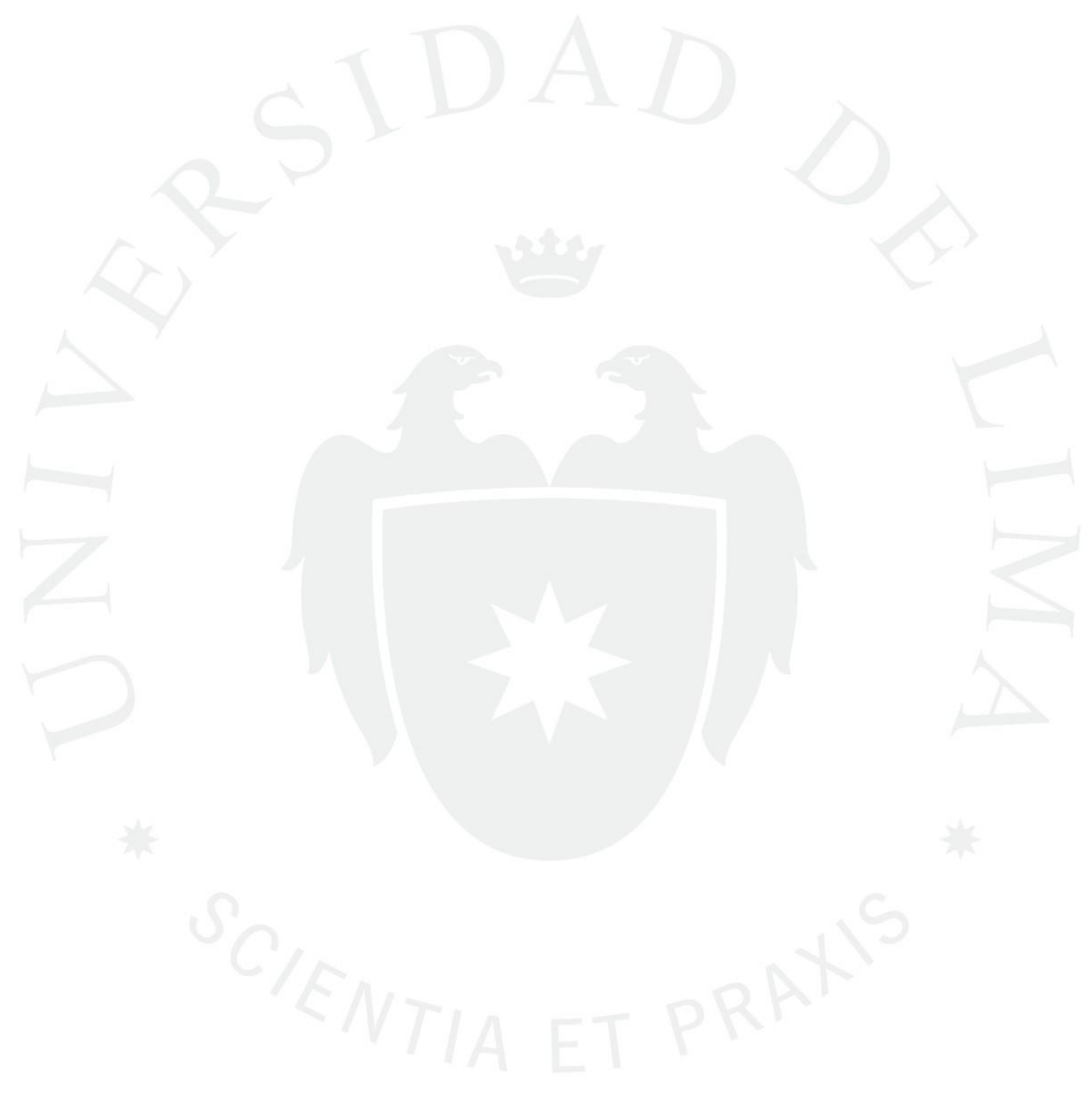




\section{LA IMPORTANCIA DE LA COMUNICACIÓN INTERNA EN ORGANIZACIONES DEL TERCER SECTOR: CASO ENSEÑA PERÚ}




\section{RESUMEN}

En el Perú, la educación es la principal problemática que atienden las organizaciones sin fines de lucro (Portocarrero \& otros, 2001). Enseña Perú es una asociación que trabaja con un modelo internacional, el cual, a través de un programa de liderazgo para profesionales, aspira a que en el año 2032 más niños tengan una educación de calidad. Se tomó como caso de estudio la misma con la finalidad de investigar la comunicación interna y cultura organizacional en el tercer sector. Se buscó identificar las estrategias de comunicación que permitan consolidar la cultura de la organización para generar compromiso en sus colaboradores y obtener resultados deseados. Así, se trabajó con una investigación mixta, involucrando al público interno de Enseña Perú. Como resultado, se halló que la comunicación interna es deficiente, provocando que la cultura organizacional no sea compartida por igual con los colaboradores y que el grado de compromiso de los mismos no sea alto. Esto conlleva a que se tenga menos embajadores de marca y que los puntos de contacto entre el sector privado y la organización no sean fuertes.

PALABRAS CLAVE: Enseña Perú, tercer sector, identidad, cultura organizacional, reputación, comunicación interna. 


\section{ÍNDICE}

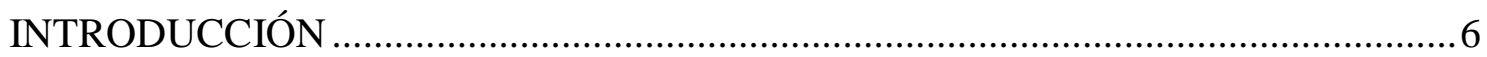

1. ENSEÑA PERÚ, UNA ASOCIACIÓN SIN FINES DE LUCRO .............................. 8

2. COMUNICAR EN UNA ORGANIZACIÓN ....................................................... 10

3. ESTADO DEL ARTE …............................................................................... 12

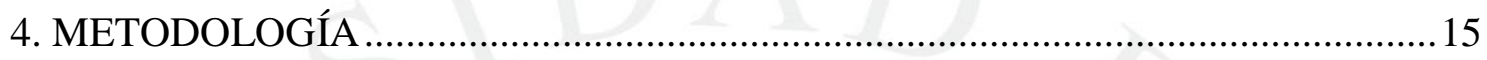

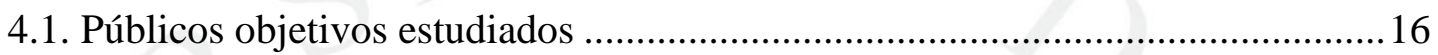

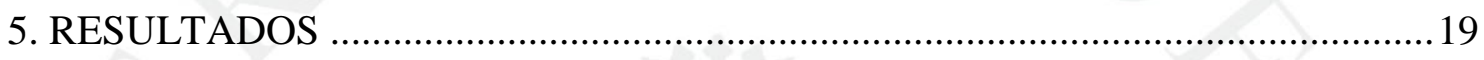

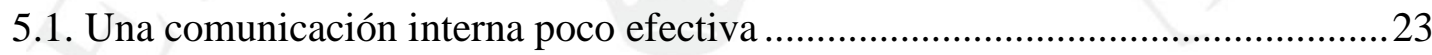

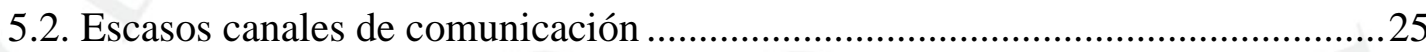

5.3. Una difícil tarea: comunicar una identidad sin una estrategia de comunicación

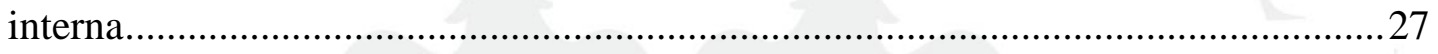

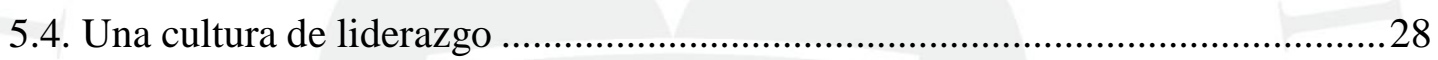

5.5. La motivación e integración de los colaboradores .............................................. 30

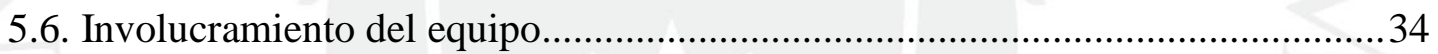

5.7. El sustento económico depende del equipo y su reputación ................................34

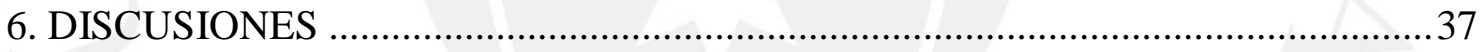

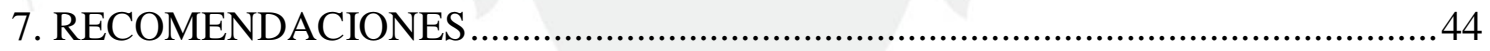

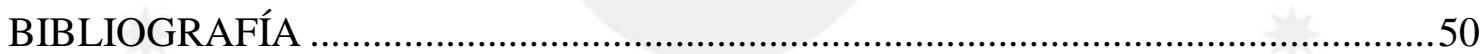

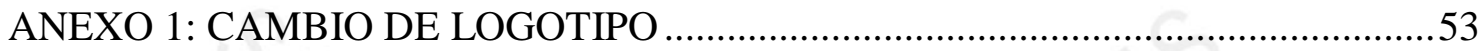

ANEXO 2: DECLARACIÓN DE POSICIONAMIENTO CREADO MEDIANTE EL

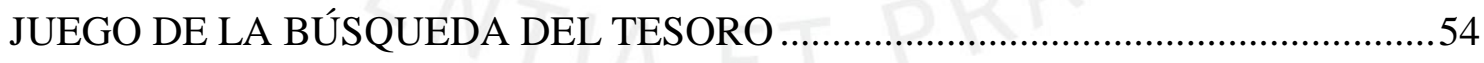

ANEXO 3: ENCUESTA APLICADA A LOS TRES PÚBLICOS OBJETIVOS ..........55

ANEXO 4: GUÍA DE PREGUNTAS PARA LAS ENTREVISTAS AL STAFF .........59

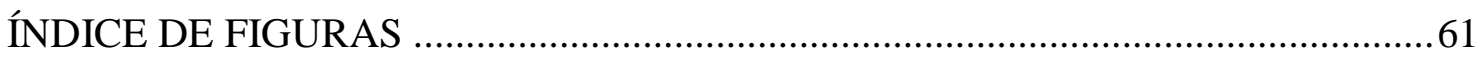

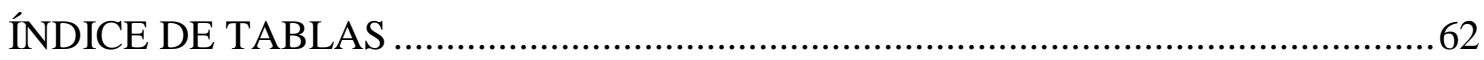




\section{INTRODUCCIÓN}

El tercer sector es un término que apareció en la década de los setenta, en "The third sector new tactics for a responsive society", en el que describe a este como un espacio de actuación público que no cubre ni el Estado ni el mercado (Balas, 2011). A este sector pertenecen organizaciones no gubernamentales (ONG), asociaciones, colectivos, entre otros, los cuales prestan servicios sociales que el Estado no realiza. Asimismo, a este sector pertenecen:

Organizaciones que emergen de la libre iniciativa ciudadana, con el propósito primordial de ofrecer servicios de carácter social a la comunidad o a sus asociados, los cuales pueden ser de variada índole. Son de carácter no gubernamental, no persiguen beneficios económicos y sus miembros aportan voluntariamente su trabajo (Ganga, Juan \& Máximo, 2010).

Algunas de las problemáticas a nivel social que encontramos en el Perú son las que este sector busca apoyar; es decir, disminuir la baja calidad educativa y problemas de salud pública. Así, la educación es la principal actividad de las organizaciones sin fines de lucro; cerca de tres cuartas partes del empleo del sector son dedicadas a la educación (Portocarrero \& otros, 2001).

Con la finalidad de estudiar la comunicación interna en organizaciones del tercer sector, en el país, se eligió estudiar el caso de Enseña Perú. Como cualquier organización — privada, pública o sin fines de lucro-, necesita de la comunicación, tanto interna como externa, pues es el único medio que permite comunicar quién es, qué hace y cómo lo hace y asimismo porque es una herramienta estratégica para la gestión.

Por ello, la presente investigación tiene como objetivo identificar las estrategias de comunicación interna de las organizaciones del tercer sector que permitan 
fortalecer una cultura organizacional sólida. De esta manera, la organización pueda generar compromiso en sus colaboradores para obtener resultados positivos, como lograr la meta educativa. Es así como se parte de la siguiente hipótesis: las organizaciones del tercer sector tienen un problema de comunicación interna que provoca una falta de fortalecimiento de la cultura organizacional en estas mismas, influyendo directamente en sus objetivos y resultados. 


\section{ENSEÑA PERÚ, UNA ASOCIACIÓN SIN FINES DE LUCRO}

La educación es un factor importante para lograr un desarrollo sostenible mundial. Enseña Perú es una asociación sin fines de lucro que pertenece al tercer sector y se enfoca en mejorar la educación del país. Nació en 2009, en el Perú, y forma parte de la red internacional Teach for All. Su visión es que aspira a que, en el año 2032, ocho de cada diez niños y jóvenes peruanos recibirán una educación de excelencia. A partir de ello, ha diseñado un programa de liderazgo para formar a un movimiento liderado por agentes de cambio ${ }^{1}$ que desde su experiencia contribuyan a eliminar la inequidad y la baja calidad educativa.

Se trata de un programa de dos años en el que seleccionan a profesionales para que enseñen, como profesores, en colegios públicos de zonas vulnerables, aportando desde sus conocimientos una mejora a la educación. No es un voluntariado, como lo son muchas de las organizaciones de este sector. Su valor agregado y ventaja diferencial es que remunera a los profesionales que recluta y los forma dentro de un programa de liderazgo, donde no solo van a enseñar a niños en situación vulnerable, sino que también adquieren capacitaciones y conocimientos de cómo ser líderes. De esta manera, cuando regresen a sus puestos de trabajo, en el mercado, tendrán otra visión de lo que

\footnotetext{
${ }^{1}$ Agentes de cambio son todos aquellos actores que forman parte del programa de liderazgo, actores del sistema que pueden impactar en las empresas, instituciones y gobierno y los mismos donantes que no solo participan como actores financieros, sino también como empleadores de los líderes que forma Enseña Perú.
} 
puede ser la educaci6n en el pais y, desde donde se encuentren, aporten y mejoren la mtsma. 


\section{COMUNICAR EN UNA ORGANIZACIÓN}

La comunicación interna es el diálogo entre la dirección y los trabajadores, un constante feedback entre las partes. Se trata de gestionar el flujo de mensajes que nacen, se reproducen y circulan en todas las direcciones, dentro de las organizaciones. La finalidad es organizar y promover este flujo de información que circula por los canales internos y que contribuye a obtener resultados como motivar e integrar a los colaboradores, coordinarlos, transmitir objetivos, difundir las políticas, construir la identidad de la organización, crear un clima de confianza, etc. (AEDIPE, 2011).

Al igual que las personas, las organizaciones son únicas, tienen una identidad, pues cada una tiene su propio sello que la caracteriza. En ella está inscrita su singularidad, personalidad y estilo de la organización (Costa, 2011). La identidad es la esencia y para percibirla es necesario que se transforme en acción. Así, para Joan Costa, la cultura es el vector que hace real la identidad y para ello ha de ser expandida, compartida, aceptada y asumida por quienes integran la organización (Costa, 2011).

Identidad, cultura y comunicación interna son tres elementos que van de la mano en una organización, pues la última permite fortalecer la segunda entre los colaboradores para que a su vez se identifiquen con la primera. De esta forma ellos, conociendo la identidad y la manera en como actúa la organización, podrán sostener los mensajes que la misma pretende comunicar. Asimismo, es importante que todos los actores y mensajes estén alineados, pues de ello depende la reputación.

La reputación es un valor intangible que necesita tener y debe gestionar una organización. Es la mezcla de la realidad de la organización relacionada a su comportamiento, su actividad económica, la calidad que ofrece, su ética, su responsabilidad social, entre otros aspectos que esta ejecuta y el reconocimiento por 
parte de los stakeholders de la misma realidad. Se trata de poner en valor lo que la empresa hace y logra a través de una herramienta: la comunicación interna y externa (Villafañe, 2013).

Enseña Perú trabaja con una estrategia de fundraising. Como la mayoría de las organizaciones que pertenecen a este sector, necesita de las donaciones de instituciones y/o filántropos para poder existir, más aun cuando debe remunerar a todos los miembros de la misma. Por ello, es importante gestionar la reputación en organizaciones del tercer sector ya que este intangible es uno de los principales que va a permitir generar confianza en el entorno y así atraer un mayor número de financiamiento por los empresarios. Carreras menciona que "una buena reputación permite ganar y mantener la confianza de los grupos de interés y por eso se convierte en la herramienta de la gestión para fortalecer la confianza" (2013, p. 25).

La reputación interna es la identificación de un colaborador con su organización, la admiración que sienten estos por la misma, "es el grado de convergencia entre la cultura organizacional y el proyecto empresarial" (Villafañe, 2013). Es importante este factor reputacional, pues involucra a todos los colaboradores de la organización y el orgullo que sienten por ser parte de ella, alineándose con la identidad que es la esencia de la organización. Para que haya reputación interna, es necesario una buena comunicación en función de objetivos que permitan coordinar, así como funciones y formas de hacer el trabajo. 


\section{ESTADO DEL ARTE}

Como antecedentes a la presente investigación, se ha estudiado el tercer sector y la importancia de la comunicación para el desarrollo del mismo. Se han hallado algunos estudios donde se aborda la comunicación en este sector y otra investigación sobre casos específicos.

Se reconoce que la comunicación tiene una importancia estratégica para el tercer sector, pero no hay convencimiento de su valor estratégico para la gestión de personas, como lo asegura Montserrat Balas (2011) en la investigación que realiza en España sobre la gestión de la comunicación en este sector. La misma carece de un planteamiento estratégico y a su vez de un área y una persona que se encargue de las comunicaciones. Las organizaciones entienden la comunicación de manera instrumental, utilitarista y enfocada al corto plazo. Asimismo, consideran que es un medio para alcanzar determinados fines, como dinero y voluntarios. De ahí que estas organizaciones no realizan una segmentación de sus públicos objetivos, ni utilizan herramientas para medir la eficacia de su comunicación, pues priorizan otro tipo de estrategias, como las relaciones públicas que tienen bastante éxito. En relación a su comunicación interna, considera que es manifiestamente mejorable. Laporte investigó que las organizaciones estudiadas no cuentan con un plan de comunicación interna; asimismo, plantea que la organización debe proponer su identidad de modo atractivo para sus empleados y voluntarios (Balas, 2011, p. 234).

En los casos de América Latina — por ejemplo, en Argentina-, La Porte (2005) menciona que el voluntariado ha crecido considerablemente. Sin embargo, a pesar que ha habido un crecimiento del sector, Eugenia Etkin (2012) comenta que la mayoría de estas organizaciones no tienen la dimensión como para conformar un área 
de comunicación interna. Por ello, La Porte señala que, cuando una organización tiene dimensiones reducidas, es conveniente que se determine quién realizará las tareas, pues son excesivamente importantes.

En la investigación que La Porte lleva a cabo sobre cómo aprovechar las herramientas de comunicación y potenciarlas en una organización non profit, un recurso valioso del que habla es el "trabajo en equipo, trabajo en red". Se rescata esta herramienta, pues Enseña Perú es una organización que trabaja en red. Asimismo, el autor señala que este modo de trabajo tiene una importancia decisiva porque muchos voluntarios disponen de un tiempo muy reducido y la tecnología les permite romper las barreras de tiempo y espacio. De igual manera, concluye que las posibilidades de trabajo en este sector son enormes y el desafío está en saber adaptarlo a las necesidades de la institución, saber reinventarlo.

Durán y Fernández (2010), en México, afirman en su investigación que existe un bajo nivel de organizaciones del tercer sector (OTS) a diferencia de otros países en la región, como Chile. Los autores comentan que este tipo de organizaciones deben reforzar la confianza en ellas, así como su reputación. Por ello, la comunicación organizacional constituye una estrategia. La confianza es un factor fundamental para la construcción de una cultura solidaria y de corresponsabilidad social. Así como Balas, Etkin y La Porte, la fundación ESPLAI considera que el punto débil de las OTS son sus estrategias comunicativas: "La gente no nos conoce o nos conoce mal, a menudo no conseguimos captar su interés" (Duran \& Fernández, 2010). Asimismo, la gestión de la comunicación en las OTS es una herramienta de socialización y cohesión dentro y fuera de la organización, no únicamente como estrategia de difusión. Por ello, deben aprovecharla para generar compromiso en su voluntariado y credibilidad y confianza en sus donantes y en la sociedad. La comunicación debe convertirse en un elemento generador de capital humano (Duran \& Fernández, 2010).

Rodríguez y Quezada (2007) estudiaron tres organizaciones ${ }^{2}$ chilenas del tercer sector, abordando los temas de cultura y comunicación. Así, demuestran los cambios

\footnotetext{
${ }^{2}$ Las tres organizaciones estudiadas son: Un techo para Chile, Hogar de Cristo y Corporación de Ayuda al Niño Quemado.
} 
exitosos de cultura que experimentaron estas organizaciones. La razón del éxito es que incorporaron conocimiento profesional a su gestión. Lograron un cambio en la cultura y de actitudes dentro de la organización. Una modificación importante fue la de aceptar que estas instituciones fuesen gestionadas de acuerdo a principios de administración aplicados en organizaciones productivas con fines de lucro, utilizando modelos de gestión del sector privado. Al lograr ello, salieron de su marco de operaciones que les impedía mejorar sus fuentes de financiamiento. Las organizaciones realizaron campañas y alianzas con empresas privadas, utilizando estrategias de marketing y recolectando fondos, que antes no se pensaba pues todo contacto con el sector privado era a partir de mecenazgos o patrocinios. Por otro lado, evidencian que un cambio notable fue pasar de una concepción asistencial del cumplimiento de la misión a una de intervención:

Esta última se preocupa de generar redes entre los mismos interesados, para que asuman la responsabilidad que les cabe en la solución de sus problemas. Todas las organizaciones seleccionadas y muchas otras pertenecientes al tercer sector han dejado de centrar sus actividades en remediar o paliar una situación social aflictiva, para ocuparse principalmente de su prevención (Rodríguez \& Quezada, 2007, p. 147).

A partir de estos cambios en la cultura, la misión ha seguido intacta y los valores que inspiran a sus voluntarios y empleados también. 


\section{METODOLOGÍA}

Investigar sobre cultura organizacional es estudiar la comunicación de una organización y viceversa. Un eje transversal en el desarrollo de la cultura es la comunicación, sin la cual aquella no puede irradiarse (Sheen, 2016). Asimismo, Losada (2004) comenta que la cultura determinará en gran medida el proceso y desarrollo de la comunicación interna y viceversa, llegando a ser uno de sus factores determinantes. Cultura y comunicación son, en el ámbito empresarial, dos términos estrechamente unidos.

Se abordó la problemática desde la investigación mixta, con un estudio cualicuantitativo, con la finalidad de complementar y contrastar información de acuerdo a los públicos objetivos estudiados. El trabajo de campo se realizó entre los meses de septiembre y octubre de 2014.

La investigación cualitativa se llevó a cabo a partir de un muestreo por juicio, en el que se seleccionó a un conjunto de colaboradores (cinco), gerentes de cada una de las áreas que componen la organización. El criterio de selección se hizo de acuerdo a la teoría de que los líderes son quienes transmiten y tienen conocimiento de la cultura. De acuerdo a Sheen:

[...] los líderes son los ejecutivos o funcionarios que encabezan equipos de trabajo y tiene sobre ellos funciones de dirección, supervisión y control. Estas personas, responsables de guiar, influenciar y enseñar a sus colaboradores, son agente transmisores de la cultura a través de sus comportamientos (Sheen, 2016, p. 40).

Se llevó a cabo la investigación cuantitativa de tipo no probabilística donde la muestra se realizó por conveniencia. Del universo de la población, se eligió una muestra 
por cada grupo que integra la organización. De acuerdo a Aguilar (2009), se seleccionaron variables para estudiar la cultura, como son: el perfil de la organización, la comunicación interna, elementos del clima organizacional, símbolos, liderazgo, motivación, capacitación y actitudes y valores, los cuales permitieron dar un diagnóstico de la cultura organizacional.

Las técnicas empleadas fueron las entrevistas a profundidad y encuestas (ver anexos 3 y 4).

\subsection{Públicos objetivos estudiados}

Para llevar a cabo la investigación, se segmentó a los colaboradores, siendo cada uno de estos grupos una población estudiada: el Staff, los Profesionales de Enseña Perú (PEP) y los Alumnis. En este estudio se trabajó con el personal que radica en Lima, como primer acercamiento a la investigación, pues se trata de la sede central. Posteriormente, se podría ampliar la investigación realizando las encuestas a nivel nacional.

\section{Figura 4.1}

\section{Grupos de colaboradores de Enseña Perú}

\section{STAFF}

7 Gerencias.

Muestra del estudio: 17 colaboradores de 20 a 30 años de edad encuestados nertenecen a la Generación "Yó.

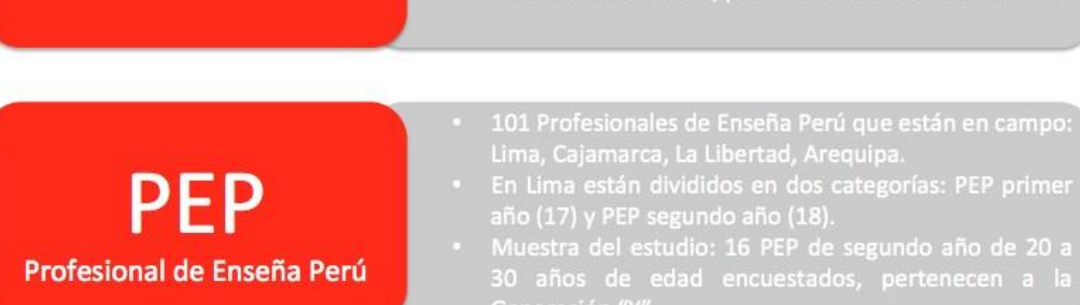

\section{ALUMNIS}

Profesional de Enseña Perú-

Egresado

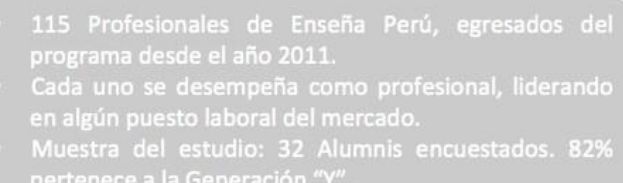

Fuente: elaboración propia según entrevistas. 
El Staff fue encuestado a través de una plataforma virtual, pues todos los colaboradores no se encontraban a tiempo completo en las oficinas: muchos de ellos estaban en el campo visitando y supervisando a los PEP; otros, en reuniones o trabajando desde sus hogares. Por ello, la encuesta presencial dificultaba el trabajo de campo. Se aplicó el cuestionario a diecisiete de ellos de las diferentes áreas de la organización, de un total de treinta.

Enseña Perú está dividida en siete áreas que corresponden a las siete gerencias. Cada una de estas, liderada por un gerente. Así, tenemos el siguiente esquema:

\section{Figura 4.2}

\section{Organigrama de Enseña Perú}

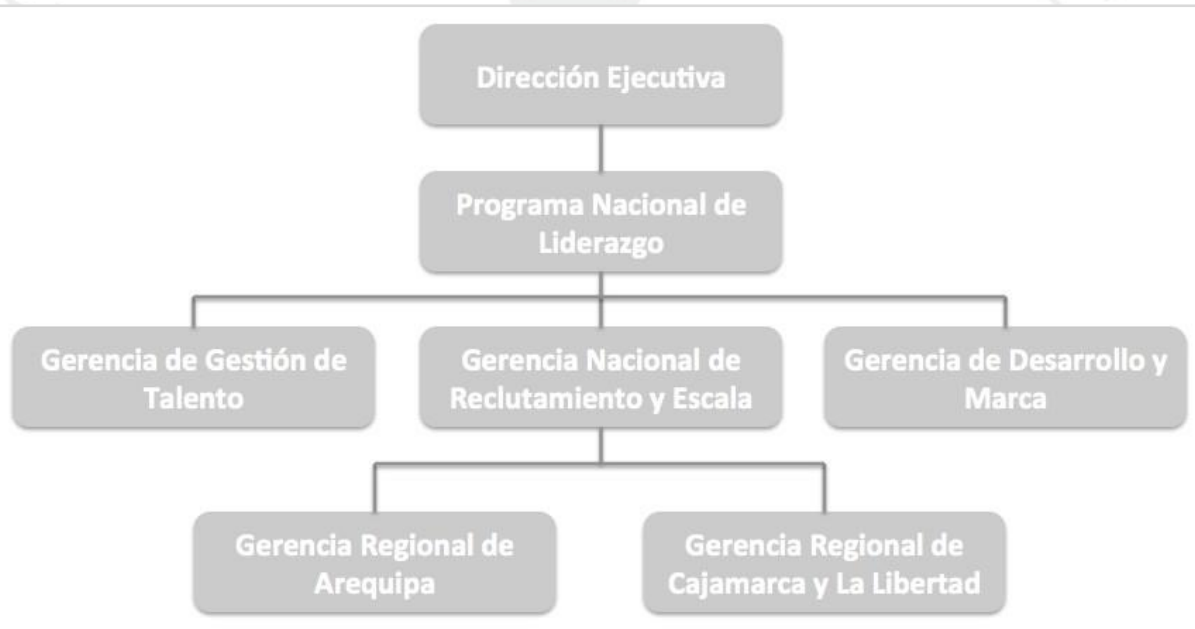

Fuente: elaboración propia según entrevistas ${ }^{3}$.

Las entrevistas a profundidad se realizaron a cada representante de área de Lima:

- Franco Mosso. Director Ejecutivo de Enseña Perú.

- José Revilla. Gerente del Programa Nacional de Liderazgo.

- Paola Balvin. Gerente Nacional de Reclutamiento y Escala.

- Aldo Valencia. Gerente de Desarrollo y Marca.

${ }^{3}$ Este esquema no corresponde al organigrama oficial de la organización. Fue elaborado como resultado de las entrevistas realizadas, debido a que a la fecha no contaban con un organigrama. 
- Guiliana Rivas. Coordinadora Nacional de Gestión y Talento.

En el caso de los PEP, la encuesta se llevó a cabo de manera presencial en las oficinas de Enseña Perú. Se encuestó a dieciséis de dieciocho PEP de segundo año. Se eligió trabajar con este grupo, pues, al ya haber pasado más de un año dentro de la organización, están más inmersos en ella y la información podía resultar más completa. Ellos ya han vivido la cultura, a diferencia de los de primer año que recién iban a ser impactados. Asimismo, permite identificar si después de un año existe un compromiso o no con la organización y qué tanto se sienten parte de la misma, antes de pasar a ser Alumnis de la red Enseña Perú. Este proceso se hizo durante una jornada, donde cada PEP debía presentar un proyecto que aterrizaría en la comunidad en la que trabajaba.

Finalmente, se encuestó al grupo de Alumnis egresados del programa de Enseña Perú. El proceso se hizo a través de una plataforma virtual, pues cada uno de los ciento quince se encontraba trabajando en algún puesto del mercado. Se encuestó a treinta y dos Alumnis ${ }^{4}$.

\footnotetext{
${ }^{4}$ Cabe resaltar que algunos de estos pertenecen hoy al Staff de Enseña Perú. Por ejemplo, el Director Nacional del Programa, la Gerente de Reclutamiento y Escala, Coordinadora Regional del Programa de Liderazgo en Cajamarca, Coordinadora Regional del Programa de Liderazgo en Cajamarca, Coordinador Nacional de Relaciones Gubernamentales, Coordinador Regional de Gestión Institucional y Desarrollo de Arequipa.
} 


\section{RESULTADOS}

Los tres grupos de colaboradores de Enseña Perú no tienen las mismas percepciones respecto a los diferentes elementos que se investigaron dentro de la organización, si bien los tres viven día a día la misma cultura. Se obtuvo respuestas variadas sobre la comunicación interna, los canales empleados, la identidad, la cultura, los valores, el liderazgo, la integración, la motivación, el ambiente laboral y el compromiso. A continuación se presenta los cuadros con los principales resultados: 
Figura 5.1

\section{COMUNICACIOI}

Comunicaci6n en areas: ES BUENA

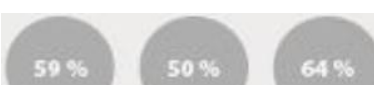

STAFF PEP AWMNIS

Comunicaci6n entre areas: ES MUY BUENA BUENA $33 \%$

STAFF PEP STAFF PEP

\section{$9 \%$ \\ $52 \%$ \\ ALUMNIS \\ AWMNIS}

Canales de Comunicaci6n

STAFF 9416 Cono tltclrclnko 71,.Rttnlonts

PEP $100 ! 6$ Conto tltclrclnko $\mathbf{S}$ Rtclts Sodllti

AWMNIS 91116 Coneo tltctrclnlco 67!16 Conpiiitros

Colaboradores informados .eon fl'!Cilenci.l informan 10 que pas:f

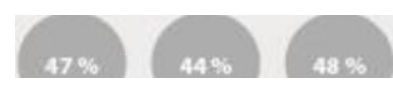

$$
\text { STAFF PEP AWMNJS }
$$

Relacion supervisor-colaborador

"Siempre misuperior inmediato esto1 disponible cuando i o R!QUiero•

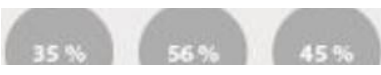

Principales resultados de Ia investigacion cuantitativa
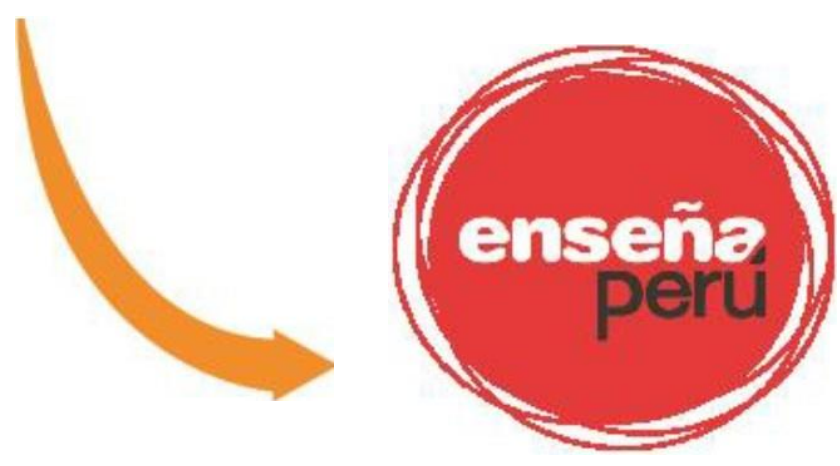

\section{IDENTIDAD}

Misi6n y Visi6n: ESTAN MUY DERNIDAS

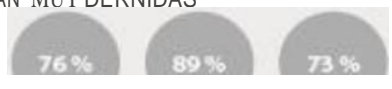

$$
\text { STAFF PEP AWMNIS }
$$

Objetivos:

-serun movimiento iiderado por < gentes de cambia"

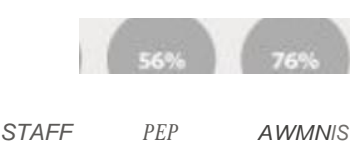

Valores

STAFF 1 Ptrstvtrandi a8!li Stntldocit pOJI.IIdid

PEP $\quad 93.8$ K Stntldocit posl.lldid 88!li Ptn.vtrandi

AWMNIS 91\% Stntldocit posl.1ldid 82:16 Ptn.vtrandi

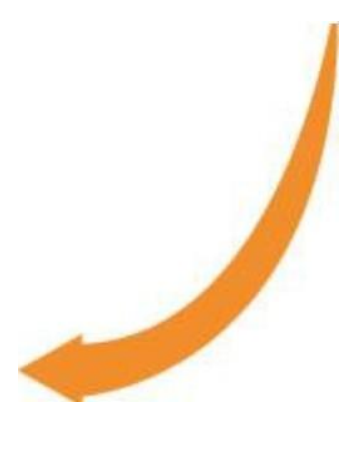

"Siempre nos felicit<In cuandlo rt>alizamos bienel trabajo'"

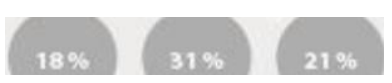

STAFF PEP AWMNIS

Integracion

"Siempre existe unamlstica que estamos toclos juntos"

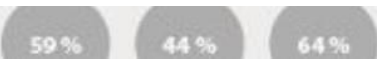

STAFF PEP AWMNIS

Trabajo en equipo

"Confrecuenclatrabajan enequlpoy coordinados"

\section{\begin{tabular}{lll}
$47 \%$ & $50 \%$ & $45 \%$ \\
\hline
\end{tabular}}

$$
\text { STAFF PEP AWMNIS }
$$

Confrecuencia requieren apoyoyes r.lpido en Ia medida delo posible"

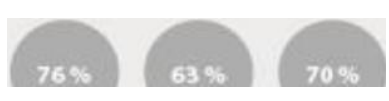

$$
\text { STAFF PEP AWMNIS }
$$

Compromiso

"Siemprt> Ilevo la misi6ny visiOnprt>sente en eldla adla" 


\section{Figura 5.2}

\section{VARIABLES}

OOMUNICACION INTERN-

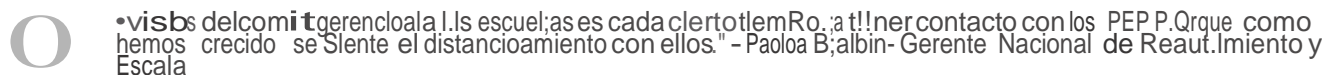

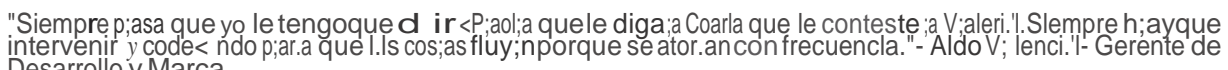

"Lounko que tenemos como aa:i6nconcreb es unvideo par. Olle estntoclos comunicados de las grandes

"Vr:l' norm< Imente unwzconmiequipo gerencial un<wz;almes v;amostodos juntoes un;a form<l deest;ar hi:'-Fr.Inco Mosso. Director Ejecutivo

'La gente es autodirlgid;a. se sienten como en su $\circlearrowright$ es un . . g:ar clonde se trabaj;a pol' objetivos.- Aldo Valencia- Gerente de Desarrollo yM;arca

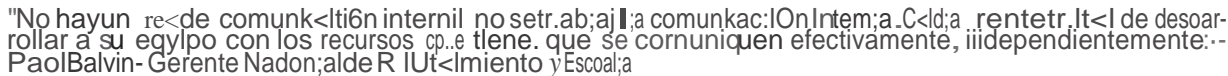
•creo que cacl.I gerente, busc;a que sus equipos se invo.,.crenhay distintos ritmos dentro de los equipos de Ensena. No siempre se PI!ede hacer un<cogestandari:uda p;ar.a todo pero silo hablamos contlnu;amente, e c6mo vamos a comunkary a proveer experienci. Is o entretenimiento. - Fr. anco Mosso- Director Ejecutivo

\section{INTERPRETACI6N}

No existenP.rocesos comunk<ldon;ales lo que no permite des;arollar una cornuni ;aci6nef tiv;a.

l.a comunkaci6n Int!!rn;a es deficiente, se idencl.1 mas entre las

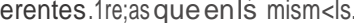

Ucomunkxi6n entre los gerentes es mejor que elresto del ruff.

Evidenci.l' de un problem<no comunicacional relxion<ldo alcomproEvidenci.'. de un problem<no comunic
miso y motivaci6nde; ayud;ar; alotro.

Cl;aridad delos roles. Se I) Pne a lo anterior. pues no todos est.1n inform<ldos y oalmomento
de irfformoar no se s:abe a quk!n d;ar el mensaje pol' lo que los roles no esbrfanbiendefinidos. No Ileaanlos mens;ajes a tiempo lo que podrl;a gener<r problem;as con
elfull)(3r.a1Sing (de esb estr.ateg101 es que pue <fe m<lntenerse l.1 orga-
n1Zacion).

Los Alumnis vivieron los mismos problern.1s que los PEP bmbk!n e $n$

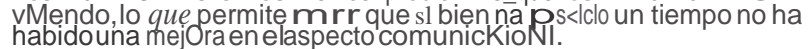

RealiLln visit</reuniones uno ;a uno, segun el staff. Sin embargo, par.a PEP no enmuy presentes.

1;1 flujo l;a comunlcaci6n se ;atora. Es d ir los mensajes no lleg;an a

Re011iL1n un video pero no es mencionaclo por los PEP como c;an< $<$ de
comunicaci6n,Lo que 1 mplica que; ;alln no esta bien posicionado como Comunicaci6n, Lo Re<l izanvisibs, reuniones unoa uno, segunel st<lff. Sinemb;argopar; a los
PEP no est.1n muy presentes.

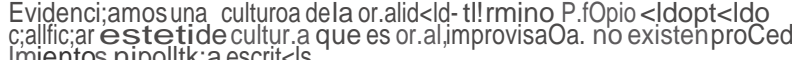

Evidenci;amosun.1 cultur.a de 1.1 oralid<ld- t rmino P.ropio acloptado p;ar;a alficar este tipqde cu ur.a que es or.al improvis;aO;a , no existen proced mientosnipolitic<escritas.

Evidenciamos Iln.1 rultur.a de la or.alidad- tQrmino PfOP.Io aclopudo P.ar.a calific:ar estetipo de cultura que es or.ll improvis da, no existen procedimientosnipc lltc; a escrit<ls-.C da rea vive de rnanera distint; alcultur.ay depende 


\section{VARIABLES}

\section{PERCEPCIONES}

"H<ICQ I.XIOS < noli. (. - ), nosotros ni siQUier:I dl! cbmos quQ Qr; un program;a dQ lidQl,IZgo. Be h;a sldo un c;ambio

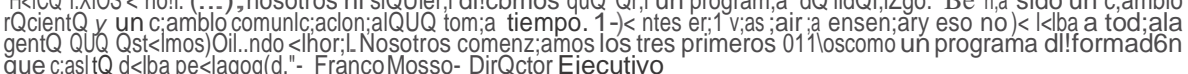

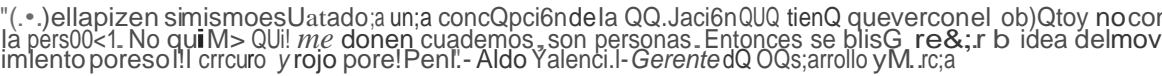

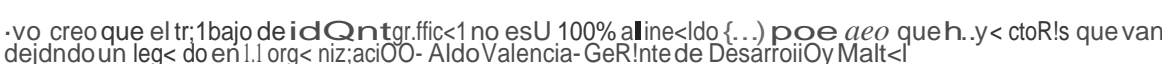

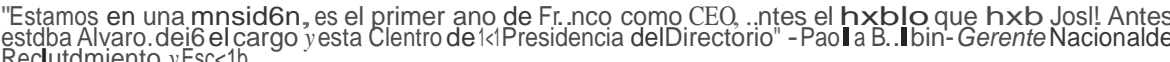

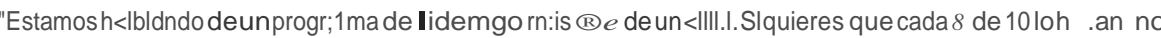
essltr;:IWS de los ninos impact.iidos en dUb sinocon los PEP quese convierten enrlderes cambian el sistema
-AldoV..I enci.l-Gerente de Des. rrollo yMarG

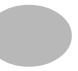

\section{INTERPRETACION}

La identldad se ha detinido poco < 1 poco, hoy exist!! mayor cbrid<ld, lo
QUll! es postlivo par: 1 Ja orgamzaci6n.

Hhabido uncambio en bidentidadg tic; a luego de definirs $Q$ como un program<de liderazgo, ; aspacto pos tivo tamDil!n a resoaltar. Ambos
puntos permiten comprometer ma los miembros deb org< nizxi6n.

Tras haber realizado cambloli. aun quadan QjQmentos por de!Onir.Todo

EJ LJdQr :!Un no Qst.1 bien posiclon.1do pues !leva poco tlempo en el

Sedetinen como un progr;1ma.TIQne cl.1ridad en ello. B objetIvo son los PEP, nolas.tuloas.

"L. construcci6n de $1.1 \mathrm{im}$. gen, los mens;ajes de marc.. es un. cumplircontre escuch<lr bien la compri,ir, identificar, utilizarlo tener un;a pr. IctiQ (...)-Aldo

"Cuando algulen redbe oalgQ de I oa otr; 1 area, no slente que es p;arte de such<lmba y lo slente comoun extra. entoncQs como noes de mi area lo busco cuando pue<la: - JOsi! Revill.l- Gerente

-sr Pols< que entre reas, no tr; $1 \mathrm{bOl}$ mos coldbor..tivamente como nos reunimostod;; as bs sem< nas. - Aldo Vdlencl.l-Gerente de OQs;arrollo yMar-c

"Conel Staff nosesa es Ia priroorarespuesta Con los PEP es el Conelo de Progr; 1 m01 Nxioodl de Uder. Zgo

-(...) buscamos reconocer quivive los $\mathrm{V}<$ llores cado semoana(...), dlnos qunesUvlvlendo tal valor bien $y$ por qu-Fr; 1ncoMosso-Director Ejecutivo

"(...)deberlamos h;acQrlo Qn las otr;:Is MQall. dQ hecho fnseno PQnHenlaun retlro un;a wz;!! ;ano_ QUQ en princlpio silosfondos v;anbien, en noviembrQ dll.berf.1mos tenQruno. (.. solo quQ c;adoa wz qIJII!crece EnsQn<I sevUl!!IW un poquito mas complicoado-JoRevilloaGerente de Program<Noacionoal da Uder;:Izgo

"En enM>tenMJos un retiro p:ar;:11.1nL1r el segundo.1noy oalfin< Idel D1110 tambil!n tenemos un encuentro de dos dfas. Iemeternosboast<Intea los retiros porqoosonmomentos delano donde se encuentr..n (...) en elmffno hay mucho deesto. Deberf;a habery QS cierto porqlJI!! QS un equipo nuevo.- Josl! Revil ;aGerentede PI"09r;Imoa Noaci o- n;alde Uder;1zgo

"En principia Qdoa dos o t!Qsrooses tQnf mos l;a cu1tur; 1de sldff,creo qUil se debi6 instltudonaliz:ar. Sejuntel $\mathbf{s} \boldsymbol{y}$ hay un<1 premidabn con ell piz de oro quil se lo damos a loa persona que logr6 algo."- Josli Revilld- Gerente de Progr;1ma Nxlon;alde ider;Izgo

-con Ios PEP es el moroonto INVE. donde vlven los v:alores. Tenemos v:arias reunlones de cultur; 1, oarnnan los valores, h cen los slogn ahres CU<Indo irool mos ellider;:zgo." los!!Revilla-GeR!nte de Progr:1ma N<cion;al de Ider. Zgo 
"En eiiNVE SQ

R!Spir;llo que

q|Jll!remos $y \mathrm{~s}$

tr; 1baja b

mnte eso,

por ser un

intern..do

termina slenclo

un;a familia -

.los!! Revilld-

Gerentede

Progr;1ma

lidar $<\mathrm{IZgO}$

-Dasde el inkio

eroa muy

defensor d

moantener loa

cultoo, $<$ mrstic;

a, paro v;a

requiriendo

mas trabdjo por

;ahara somos

muchos

mas.Estos temas

elcomitl!de

romo vamos.

h.1cer par; 1que!

nose caig. 1 .

Conforrne vas

creciendo la

cultoo!Qquiere

ms tlempo y

Ensena ha

evolucionado

pid;amentela

$\begin{array}{lll}\text { primer;1 } & y & \mathrm{l} ; \mathrm{a}\end{array}$

segunda

promoci6n vivi6

un;a culturoa

Ensan;a $y \quad$ loa

tercer;l $y$ cu.1rn

otril, $y$ entonces

siempre se $\mathrm{V}<\mathrm{n}$

combin.1ndo

tod<ls est<

cultur; $15 .{ }^{\circ-}$

FrdOCoMosso

Ejecutivo

\section{Fuente: elaboraci6n propia}

Buscanquela ldQntidddse<llitoconstruy se.1 1 smile, unejemplo escon

Se evidancioa un problema no comunicdCion<L reloadonado <llcomprQ-

No exlst'|lgr; 1 ncolabor.Ici6n entre las Mea!;, Io que poode poner enriesgo
Ios objetlivos.

Se le pregunt6qoo actlvidades p;ar; 1fort<llecar la cultur:1 se real izaban, en el Stiff no lo tlenen cldro, yesto se debe a que la mayorla de dctlvid<ldes en orient<Kids a los PEP (AlINVE)

Notodoel ruffesU alinQado pues sibiQnunos mendonoan;!!gunos reconocimientos comoes loa pl1 ctlc. 1 de I os v;alorel:; en loalnvestig<ci6n cuoantltatlva loa tasa dl!!reconocimiento no QS; ;!td.

los rituoalas de cul tur, 1 no Qn institucionalizados y nose compoartenpoaroa todo el equlpo de loa org< niz;ad6n.

os ritU<lles de cultur; 1 no se comp. 1 rten par; 1 todo el aqulpo de la org.lnizaci6n. Se centr; 1 n mas en los PEP.

loa practic;a delreconocimiento. no esU insltuticlon;alizada al 100\%, en el stoiff. Elreconodmlento es un elemento que aporn;!! comproms o de los col<lboradores yes parte delsatarlo emocional.

os rituales de cultur:1 no se comparten pm todo el equl po de la org nizaci6n. Se centr;1nms en los PEP.

os ritU<lles de cu1tur; 1 no se comparten par<todo el equi po de 1.l organizaci6n.SQ centr; $1 n$ nus en los PEP.

La Culturoa no est.idQfinlda. nilo QSU p;ar; 1 qulen es elllder dQ 1.1 orgoanizaci6n. Sino esUcidr; 1 p;ar; 11 ll, menos Io estaro1 para los miembros del Staffy PEP. 


\subsection{Una comunicación interna poco efectiva}

En Enseña Perú se evidencia que la comunicación interna es deficiente. El flujo es horizontal y esto se debe a las mismas características, pues está conformada por jóvenes de la generación "Y”. Al ser jóvenes en su mayoría, ocurre que el grado de confianza es alto, hay buenas relaciones y libertad para expresarse. Sin embargo, el exceso de horizontalidad respecto a la comunicación y la cercanía entre los miembros conlleva a que los procesos sean informales, perjudicando que la comunicación no sea efectiva. "Tienen la visión clara pero hay cosas como procesos, registros, que cambia la personas y no queda nada. No teníamos nada y recién vamos teniéndolo"5.

Los procesos comunicacionales no fluyen adecuadamente, pues la información no llega a tiempo ni a todos los puntos. Se evidencia que la comunicación dentro de cada área es mejor que la que se da entre las mismas. Cabe resaltar que el 0\% del Staff dijo que la comunicación es muy buena entre áreas y solo un $31 \%$ de los PEP dijo que es buena. En los tres casos, las tasas no son elevadas, sino a penas un poco más de la mitad (ver Figura 5.1).

Asimismo, los miembros del Staff (José, Aldo y Franco) coincidieron que la comunicación entre las diferentes áreas no es buena y además que no colaboran entre ellos, pues cada persona se centra en sus objetivos (ver Figura 5.1. y Figura 5.2-V5): "Sí, pasa que entre áreas, no trabajamos colaborativamente como se debe de repente porque todos están full en sus objetivos y siempre tenemos que entrar los gerentes. Estamos más conectados, nos reunimos todas las semanas" ${ }^{\text {. }}$.

Además de un problema de comunicación, en el que se percibe que la información no se transmite adecuadamente y se estanca en algunos puntos, existe un problema no comunicacional que está relacionado al compromiso y la motivación de querer ayudar al "otro".

Si bien consideran que las funciones están definidas y los roles determinados, como mencionó el director (ver Figura 5.2-V1), se presenta una contradicción, pues

\footnotetext{
${ }^{5}$ Entrevista a Aldo Valencia (Gerente de Desarrollo y Marca).

6 Ídem.
} 
otro miembro del Staff comentó que no todos los colaboradores tienen conocimiento de quién debe manejar cierta información y por ello los mensajes no llegan, ya que no se envían adecuadamente: “[...] es un tema cultural de pensar quién más necesita tener esta información, es un tema de claridad, algunas personas se les ocurre y copian a una persona, pero no todos a los demás y creo que es un tema más técnico de dar claridad en quién tiene que estar informado en cada cosa""7.

De esta manera, se genera una falta de comunicación donde la causa del problema está en relación a la falta de manuales y políticas no establecidas. Como mencionó el Gerente de Desarrollo y Marca, se debe a que no hay registros. Al rotar los colaboradores, los documentos se pierden.

Por otra parte, se evidencia que no existe comunicación en cascada: si bien entre los altos cargos hay una buena comunicación, en los niveles más bajos esta no llega. Menos del 50\%, en los tres casos, consideró que "con frecuencia les informan sobre lo que pasa en la organización" (ver Figura 5.1): "Por ejemplo, renunció un PEP, quien lo sabe es el área institucional para hacer la planilla, lo sabe todo Programa y el gerente porque se tomó la comunicación. Pero, no lo sabe alguien en Cajamarca o en Desarrollo y Marca y justo va a ir un socio a ese colegio, y no informaron que no está el PEP, perjudicándonos" ${ }^{\text {. }}$

Los PEP mencionaron que no saben lo que pasa en las otras áreas. En la época en la que los Alumnis fueron PEP, ocurría lo mismo; es decir, no ha habido una mejora: "No se daba información de lo que pasaba en otra áreas"; "Los de provincia no tenían buena comunicación con las otras áreas", entre otros comentarios encontrados (ver Figura 5.2-V1). Sin embargo, el líder de la organización dijo que tienen reuniones una vez al mes en las escuelas y cada dos meses se encuentra con los PEP personalmente, ya sea por Skype o de manera presencial. Existe, entonces, una contradicción o bien no se cumple con rigurosidad las visitas.

Si la información no llega a todos los puntos, puede generar problemas en los objetivos planteados, como en el caso que mencionó Aldo Valencia y en las

\footnotetext{
${ }^{7}$ Entrevista con Paola Balbin (Gerente Nacional de Reclutamiento y Escala).

${ }^{8}$ Entrevista con José Revilla (Director de Programa Nacional).
} 
coordinaciones de equipo. Menos del 50\% del Staff y PEP afirmó que con "frecuencia trabajan en equipo y coordinados". Cabe resaltar que ninguno de los PEP dijo "siempre", lo cual se debe a que ellos suelen trabajar más personalmente que en equipo, ya que son profesores en diferentes escuelas y grados.

Si bien se hallaron algunos problemas respecto a la comunicación interna en la gestión del día a día, también se encontraron algunos puntos positivos. Los tres públicos estudiados tienen claro el objetivo de Enseña Perú; es decir que, a nivel comunicacional, saben lo que la asociación busca y hace. Ellos dijeron que el objetivo de la organización es ser un movimiento liderado por "agentes de cambio" y, en segundo lugar, brindar una educación de calidad. El Staff y los Alumnis apuestan en mayor grado por lo primero a diferencia de los PEP, que están enfocados en ser profesores para brindar una mejor educación, pues aún siguen en el programa. Al tener bien identificado el objetivo - la identidad "quiénes somos"-, referente a Enseña Perú, se induce que la misma está definida; es decir, "somos agentes de cambio, para brindar una mejor educación [...]”.

Lo mencionado anteriormente se relaciona con la definición de la visión. En los tres públicos, más del $70 \%$ consideró que está "muy definida". Cabe recalcar que para los Alumnis, cuando fueron PEP, solo el $42 \%$ dijo que la visión estaba "muy definida". El líder de la organización lo reafirmó: "Hace unos años [...] nosotros ni siquiera decíamos que era un programa de liderazgo""9 (ver Figura 5.1 y Figura 5.2.V4); es decir que ha habido un incremento en interiorizar la visión y se debe a que existe una mayor claridad en la organización, hacia quiénes son y a dónde apuntan: "En el 2032, 8 de cada 10 niños y jóvenes peruanos recibirán una educación de excelencia”.

\subsection{Escasos canales de comunicación}

Para lograr una comunicación eficiente y se entienda el mensaje, deben haber ciertas condiciones, como el contenido adecuado, la cantidad suficiente de mensajes, el momento oportuno para comunicar, la frecuencia y la variedad de canales. Estos

\footnotetext{
${ }^{9}$ Entrevista con Franco Mosso (Director Ejecutivo de Enseña Perú)
} 
últimos tienen que estar presentes para canalizar el flujo de la información. Es así como, para el Staff, los más utilizados son el correo electrónico y las reuniones, mientras que para los PEP, luego del correo electrónico, están las redes sociales (ver Figura 5.1); es decir, no existe un abanico de canales ni hay una estrategia de uso. Asimismo, no hay canales exclusivos para cada grupo.

En el Staff, hay reuniones entre los gerentes y en las áreas con los coordinadores. La gerencia se reúne todas las semanas y el Staff tiene noción de ello a través de videos que se estuvieron realizando con el propósito de tener conocimiento de los temas que se tratan en las reuniones. Cabe resaltar que estos videos también estaban dirigidos para los PEP; sin embargo, durante el levantamiento de información, ninguno mencionó que lo utilizaba como canal de comunicación. Uno de ellos comentó que solo se habían hecho dos hasta ese momento.

Los PEP se comunican con sus compañeros a través de las redes sociales, tienen grupos cerrados, además de comunicarse boca a boca, pues algunos viven en las mismas residencias, como es el caso de diez PEP que viven en Ventanilla. La comunicación con el equipo gerencial es escasa: solo una vez al mes el equipo visita el colegio y a los PEP, mientras que los coordinadores asisten por lo menos dos veces al mes: "Visitas del comité gerencial a las escuelas es cada cierto tiempo, a tener contacto con los PEP porque como hemos crecido se siente el distanciamiento con ellos"10. Por otro lado, la comunicación entre los Alumnis se da a través de correo electrónico y por redes sociales.

Otro hallazgo importante es la falta de institucionalización de los canales de comunicación. No existe una plataforma que permita centralizar la información. El Staff, los PEP y los Alumnis comentaron que con frecuencia requieren apoyo y se lo proporcionan rápido, en la medida de lo posible; es decir que el acceso a la información no es inmediato. Asimismo, en el caso de los Alumnis, las respuestas fueron más variadas; esto se debe a que, cuando este grupo fue PEP, la organización era más pequeña y los procesos eran improvisados, los recursos no estaban disponibles.

\footnotetext{
${ }^{10}$ Entrevista con Paola Balbin (Gerente Nacional de Reclutamiento y Escala).
} 
Un factor no comunicacional, pero que afecta de igual manera la comunicación es el compromiso, de qué tanto cada colaborador se pone la camiseta para ayudar al "otro" y lograr el objetivo. Sin embargo, si los canales estuvieran disponibles, la información estaría almacenada en un espacio en el que todos tendrían acceso y se resolvería, en este caso, el problema: "Cuando alguien recibe algo de la otra área, no siente que es parte de su chamba y lo siente como un extra, entonces como no es de mi área lo busco cuando pueda" ${ }^{11}$.

\subsection{Una difícil tarea: comunicar una identidad sin una estrategia de comunicación}

\section{interna}

Enseña Perú tiene la visión de lograr que ocho de cada diez niños y jóvenes peruanos reciban una educación de excelencia en el año 2032. Lo hace mediante un programa de liderazgo que permite formar un movimiento liderado por agentes de cambio. Esta visión es parte de la identidad de la organización, que sus colaboradores perciben como "muy definida" (ver Figura 5.1).

Hace un tiempo, menos del 50\% de los Alumnis afirmaba que estaba muy definida; hoy, el 75\% afirmó que lo está. Esto se debe a que en sus inicios la organización no tenía claro a dónde se proyectaba: "Hace unos años [...], nosotros ni siquiera decíamos que era un programa de liderazgo. Ese ha sido un cambio reciente y un cambio comunicacional que toma tiempo [...] antes era vas a ir a enseñar y eso no jalaba a toda la gente que estamos jalando ahora. Nosotros comenzamos los tres primeros años como un programa de formación que casi te daba pedagogía"12.

Como primer acercamiento, se sabe que: el qué es y qué hace está claro para sus colaboradores, lo cual indica que hay una identidad reconocida (ver Figura 5.1). Asimismo, se realizó un cambio en la identidad gráfica, se creó y lanzó un nuevo logo y se definió el posicionamiento (ver anexos 1 y 2).

\footnotetext{
${ }^{11}$ Entrevista con José Revilla (Gerente de Programa Nacional de Liderazgo).

${ }^{12}$ Entrevista con Franco Mosso (Director Ejecutivo).
} 
Si bien los colaboradores conocen la visión, hay cambios de la identidad que se realizaron y estos aun no están bien alineados con ellos; pues, para los mismos gerentes, no lo está: "Yo creo que el trabajo de identidad gráfica no está $100 \%$ alineado [...] porque creo que hay actores que van dejando un legado en la organización"13. Resulta difícil comunicar elementos de la propia organización cuando no hay claridad para las mismas cabezas de Enseña Perú.

De igual manera, cuando se les preguntó sobre la personalidad de Enseña Perú, los resultados de los tres públicos fueron diferentes. Para los PEP y Alumnis, la marca se encarna más en una mujer, mientras que en el Staff no lo tienen definido. En el caso de los primeros, se recuerda que en ese entonces eran mujeres las coordinadoras, las personas que estaban más cerca de ellos; mientras que, en el Staff, el líder es Franco Mosso y no asocian la personalidad de la marca a un personaje masculino. Esto demostraría una posible lejanía con el líder de la organización.

La cultura organizacional tiene como función crear una identificación por parte de los colaboradores hacia la organización permitiendo que se sientan identificados con valores, creencias, hábitos, compromiso y motivación para lograr los objetivos de misma (Pérez-Rosas, 2015). Esta cultura debe ser promovida por los líderes de la organización. Sin embargo, en el caso de Enseña Perú, el líder —quien vendría a ser Franco Mosso- no es percibido como tal por los colaboradores. Cabe mencionar que cuando se llevó a cabo la investigación el líder apenas llevaba un año como Director.

\subsection{Una cultura de liderazgo}

La cultura de Enseña Perú debe reflejar liderazgo y autonomía, por lo que representa y porque la imagen que debe proyectar a sus stakeholders debe ser positiva para persuadir a profesionales que se interesen por la causa.

El primer problema es que, en el caso del Staff, no está claro cómo se transmite la cultura. Cuando se preguntó a uno de los gerentes cómo logran transmitir el significado y la esencia de Enseña Perú a los colaboradores, la primera respuesta fue

\footnotetext{
${ }^{13}$ Entrevista con Aldo Valencia (Gerente de Desarrollo y Marca).
} 
que no tiene conocimiento de cómo se hace con el Staff, pero que con los PEP es en el Instituto de Verano ${ }^{14}$ donde se viven los valores (ver Figura 5.2-V6).

Por otro lado, se evidenció que el liderazgo y autonomía se manifiestan en diferentes grados en los colaboradores. Solo la mitad del Staff dijo que siempre puede tomar decisiones. Esta diferencia se ve probablemente por el grupo de gerentes y jefes. En el caso de los PEP, sus decisiones giran en torno a su desempeño como líderes en las aulas en las que impactan. El 75\% afirmó que con frecuencia puede usar su criterio para tomar decisiones. De igual forma sucede con los Alumni: 53\% dijo que con frecuencia lo hizo cuando fue PEP. La diferencia en el porcentaje se manifiesta porque el programa hoy comprende más ámbitos de liderazgo, mientras que antes se centraba en la pedagogía.

En el caso de los PEP, tienen la oportunidad de diagnosticar una necesidad en su escuela y de crear un proyecto que permita satisfacerla. Este es un primer acercamiento al liderazgo que deben ejecutar y que en un futuro cercano ejercerán cuando estén en algún puesto de trabajo en el mercado. Asimismo, otra forma de ejercer liderazgo y de ver cómo el PEP lo va a lograr al salir de Enseña Perú es con el mentor, que le es asignado en los últimos seis meses del programa. De esta manera, se ve orientado en cómo después podrá impactar en el sistema.

Respecto a las características de lo que ellos consideran su líder, para los PEP y Alumni estas son: alentador, empático y que sabe escuchar. Se manifiestan en diferentes porcentajes, pero son las características más repetidas. Se recuerda que los PEP se proyectan más en su coordinador que en el líder de Enseña Perú, pues es la persona que los acompaña en su proceso de formación; es decir, para ellos es como su líder. En el caso del Staff, las características más importantes son que sabe escuchar, es líder y empático.

Enseña Perú se define como un programa de liderazgo y los gerentes así lo consideran: "Estamos hablando de un programa de liderazgo más que de un aula. Si

\footnotetext{
${ }^{14}$ Los nuevos PEP se internan durante cinco semanas en el Instituto de Verano (INVE), con los líderes para entrenarlos a un nuevo reto, donde aprenden a vivir cada uno los valores de Enseña Perú y realizan dinámicas y aprenden lo necesario para comenzar el año escolar.
} 
quieres que cada 8 de 10 lo hagan no es a través de los niños impactados en aula sino con los PEP que se convierten en líderes y cambian el sistema"15. Por ello, es importante que el líder de la organización esté presente para los tres grupos que componen la organización y sea el mismo. Es el líder quien determinará la cultura de la organización por la forma en que las cosas se llevan a cabo.

Se evidenció que existe una "cultura de la oralidad"16. Como se vio, no existe una institucionalidad de procesos, por lo que hay una pérdida de recursos. Asimismo, si los líderes funcionan a partir de su propia proactividad, como también se halló, los colaboradores no van a estar alineados de la misma manera a la identidad: "[...] Cada gerente trata de desarrollar a su equipo con los recursos que tiene, que se comuniquen efectivamente, independientemente" ${ }^{17}$. A su vez, esto provoca que no sean buenos embajadores de marca, debido a que no se identifican a gran escala con la organización.

La cultura busca crear una identificación con los colaboradores, la misma que debe ser promovida por el líder de la organización para alinear a todo el equipo con la identidad y de esta manera puedan sostener el mismo mensaje que será comunicado a los stakeholders. Sin embargo, como comentó Franco Mosso, aun la cultura no está definida al 100\%: "Desde el inicio era muy defensor de mantener la cultura, la mística, pero va requiriendo más trabajo porque ahora somos muchos más. Estos temas los discutimos en el comité de cómo vamos a hacer para que no se caiga. Conforme vas creciendo la cultura requiere más tiempo y esfuerzo. [...] Enseña ha evolucionado rápidamente la primera y la segunda promoción vivió una cultura Enseña y la tercera y cuarta otra y entonces siempre se van combinando todas estas culturas" ${ }^{18}$.

\subsection{La motivación e integración de los colaboradores}

La motivación depende de la cultura, pues la última está formada por los comportamientos o formas de hacer las cosas, valores compartidos y convicciones

\footnotetext{
${ }^{15}$ Entrevista con Aldo Valencia (Gerente de Desarrollo y Marca).

16 Término propio para ilustrar el tipo de cultura.

${ }^{17}$ Entrevista con Paola Balbin (Gerente Nacional de Reclutamiento y Escala).

${ }^{18}$ Entrevista con Franco Mosso (Director Ejecutivo).
} 
(Pintado \& Sánchez, 2013). Asimismo, la motivación es un factor que se relaciona con la productividad de los colaboradores: a mayor número de personas motivadas, mejor será el desempeño. Así, el 88\% del Staff dijo que siempre lleva la misión y la visión en el día a día; es decir, trabajan apuntando hacia un mismo objetivo. Para el caso de los PEP y Alumnis, se evidenció en menor grado: 50\% y 59\%, respectivamente.

La diferencia entre estos grupos se debe a que el Staff construyó la misión y la visión y trabaja para cumplirla. En el caso de los PEP y Alumnis, existen razones de por medio, como el programa de liderazgo y aspiraciones propias de trabajar en el sector social. Por otro lado, si bien en la investigación cuantitativa se obtuvo un resultado elevado para el Staff, este se contrapone a lo que comentaron los entrevistados. Existe un problema respecto al compromiso de querer ayudar al otro.

Por ello, el reto está en hacer que en esos dos años la cultura sea tan fuerte que la hagan suya permitiendo que en su día a día tengan la misión arraigada y que posteriormente, cuando sean parte de los Alumnis, la sigan manteniendo en mente, con la finalidad de ejercer sus labores alineados a esa estrategia.

De igual manera, se halló que existe una diferencia entre el Staff y PEP respecto a si consideran que existe una mística de que todos están juntos: 59\% del Staff dijo que siempre, frente al $44 \%$ de los PEP. Si bien ambas tasas son bajas, en el primer grupo se evidenció mayor compromiso y por ello más motivación que en el segundo. Esto se debe a que los PEP no perciben cercanía con el back office, pues su zona de impacto está alejada y el Staff no se acerca constantemente, como lo manifestaron: en el caso de los Alumnis, 64\% dijo que siempre. Cabe resaltar que se realizó la pregunta en pasado, en este caso. Anteriormente, la organización era más pequeña, la diferencia se explicaría por ello, pues había más cercanía.

Una forma de motivar a los colaboradores es a través del salario emocional; es decir, el reconocimiento en cualquiera de sus dimensiones. Festejar los logros conseguidos recuerda al equipo la importancia del trabajo y el crecimiento que le genera a la organización gracias al aporte (Cabanas \& Soriano, 2014). Sin embargo, en este caso, la felicitación no es algo que caracterice a los líderes de la organización, ya que solo el $18 \%$ del Staff dijo que siempre los felicitan cada vez que realizaban bien el trabajo y $65 \%$ dijo que con frecuencia: "En principio cada dos o tres meses teníamos la 
cultura del Staff, creo que se debió institucionalizar. Se junta el Staff y hay una premiación con el lápiz de oro que se lo damos a la persona que logró algo"19.

En el caso de los PEP, el $31 \%$ dijo que siempre y el $38 \%$ que con frecuencia. Aquí los resultados tienen una diferencia menor. Debido a que los PEP son el centro de la operación, el Staff tiende a realizar actividades para ellos. Sin embargo, ambas tasas son menos de la mitad, lo que indica que no es una práctica frecuente. En el caso del Staff, existía la premiación del lápiz de oro, que era un reconocimiento a algún miembro que realizaba un logro para la organización en el Staff, pero no se ha institucionalizado. Cabe mencionar que para Franco Mosso sí realizan reconocimientos como el de los valores, reconocer quién vive determinado valor cada semana.

Por otro lado, un buen ambiente laboral permite también que un colaborador esté más motivado. Así, los tres públicos coinciden que las características de los colaboradores son amigables, responsables y confiables, lo que sugeriría que se trata de un ambiente ameno en el que es posible desenvolverse. El ambiente laboral está muy ligado a la motivación de los trabajadores: si bien los miembros del equipo reconocen estas características positivas, existen algunas deficiencias como las que se mencionaron que no lo favorecen.

Mantener a los colaboradores enganchados a la cultura de una organización significa lograr que la interioricen y se identifiquen con la misma. Si bien el encargado de Desarrollo y Marca tiene claro que todo es un proceso y en la organización aun no se comparte para todos los grupos, existen algunas iniciativas como haber definido el posicionamiento en conjunto con el Staff a través de juegos, como "búsqueda del tesoro" ${ }^{20}$, que permite la unión y el trabajo en equipo precisando lo que Enseña Perú es. Esto genera orgullo de pertenencia y fomenta la colaboración dentro del proceso del employer branding.

De acuerdo a los resultados, los valores de Enseña Perú están interiorizados. Se evidenció que, para el Staff, "la perseverancia" es el valor con mayor presencia. A pesar de los retos a los que se enfrentan diariamente, continúan en la línea. "Sentido de

\footnotetext{
${ }^{19}$ Entrevista con José Revilla (Gerente de Programa Nacional de Liderazgo).

${ }^{20}$ Se llevó a cabo este juego para crear el posicionamiento con ayuda del Staff.
} 
posibilidad" es el valor más importante para los PEP y los Alumnis. Cabe recalcar que este valor no existe formalmente. Está relacionado con lo que ellos llaman "pasión por resultados", asociado a que todo reto es realizable. La interiorización puede haberse dado gracias a la premiación de los valores del Staff y de los PEP.

Se han hallado algunos rituales, actividades que ayudan a fortalecer y vivir la cultura de Enseña Perú. Sin embargo, no toda la organización participa en estos. En el área de Programa, se lleva a cabo retiros donde se trabaja por el día y en las noches se comparte en equipo. "Le metemos bastante a los retiros porque son momentos del año donde se encuentran [...], en el staff no hay mucho de esto. Debería haber y es cierto porque es un equipo nuevo"21. Esto comprueba por qué algunas áreas se desempeñan mejor que otras, pues tienen mayor contacto y trabajo en equipo. Se recuerda que solo el 59\% del Staff dijo que siempre están juntos y, en el caso de los PEP, solo 44\%.

Para los gerentes, el momento en el que más los PEP viven la cultura y el momento más enriquecedor es al inicio. El Instituto de Verano es donde los jóvenes se internan durante cinco semanas con los líderes para entrenarlos a un nuevo reto y aprenden a vivir cada uno los valores de Enseña Perú. Aquí no participa todo el Staff, a diferencia de años anteriores en que lo hacían. En esta etapa, consideran que el PEP se llena de un bagaje de herramientas, pedagogía y vivencias sobre lo que significa Enseña Perú: "En el INVE se respira lo que queremos y se trabaja bastante eso, y por ser un internado termina siendo una familia",22.

Existen otros retiros - la celebración del Día del Maestro y Navidad, por ejemplo- Esto ocurre principalmente con los PEP, pues en el Staff los eventos no son institucionalizados ni frecuentes. En el caso de los Alumnis, existe un evento de integración a fines del mes de noviembre: el Encuentro Nacional de Alumnis. Además, hay capacitaciones, pero no asiste la totalidad. Se puede evidenciar que la mayoría de eventos y reuniones para compartir, así como los programas, son principalmente para los PEP.

\footnotetext{
${ }^{21}$ Entrevista con José Revilla (Gerente de Programa Nacional de Liderazgo).

22 Ídem.
} 


\subsection{Involucramiento del equipo}

Enseña Perú es una organización que no trabaja con voluntarios. Por ello, la remuneración a los PEP es un valor agregado y ventaja diferencial. Cuando se les preguntó si trabajarían en la organización sin ser pagados, las respuestas fueron variadas. El 50\% de los PEP dijo que trabajaría "a veces", si su trabajo no fuese remunerado; mientras que el 33\% del Staff dijo que "con frecuencia". No existe un alto porcentaje que lo haría sin recibir un pago. Esto es un primer indicativo de qué tan fuerte es la cultura y el compromiso hacia la misma. La remuneración no es el único factor motivacional: lograr que los colaboradores se sientan apreciados y valorados permitiría elevar esa tasa.

En el caso de los Alumnis ocurre lo mismo. Solo el $38 \%$ dijo que con frecuencia hubiese trabajado en Enseña Perú sin ser remunerado. Hoy, la organización sigue en contacto con ellos a través de las capacitaciones y los encuentros para potenciar el compromiso con la organización. Enseña Perú no ejerce un control sobre este grupo y en eso se basa la relación de confianza, por ello es que uno de sus valores es la confianza en red. Es relevante interiorizar los valores y potenciarlos, además de fortalecer la cultura; pues ellos son finalmente el único vehículo para lograr la visión, tomando en cuenta que no laboran más en la organización y de ellos dependen los cambios en la educación.

\subsection{El sustento económico depende del equipo y su reputación}

Para lograr los objetivos y por ser una organización del tercer sector, en el caso de Enseña Perú, depende de tres factores: índices educativos, aprobación política y sustento económico (fundraising) ${ }^{23}$. Precisamente, los fondos provienen de diferentes estrategias (empresas, filántropos, campañas masivas de productos, alianzas y eventos). Además, cuentan con el apoyo de organizaciones que les brindan servicios gratuitamente.

\footnotetext{
${ }^{23}$ El fundraising es el financiamiento de recursos materiales para el funcionamiento de la organización; una estrategia para obtener fondos.
} 
Recolectar fondos implica que la comunicación externa con los stakeholders sea persuasiva para convencerlos. Así, la organización ha tenido resultados positivos en su gestión a medida que se ha posicionado y afinado su posicionamiento 24 : "Depende del año y del financiamiento. El reclutamiento ahorita está volando, y seguramente con el proceso de selección van a pasar la valla 110, si logramos tener fondos los reclutamos a todos, a veces lo que ha ocurrido es que pasan la valla pero no tenemos fondos suficientes" $" 25$.

El siguiente cuadro muestra las cifras de las últimas postulaciones. Para 2014, el número de postulaciones fue elevado; sin embargo, solo seleccionaron a treinta y siete. De acuerdo a fuentes de la organización, esto se justifica por un año de crisis económica. Asimismo, se pudo actualizar que, para 2015 y 2016, el programa acogió alrededor de 50 PEP. Cabe resaltar que, después de 2014, se recuperó el número de postulantes; sin embargo, se evidencia cómo dependen de factores externos para su selección, lo que podría perjudicar sus objetivos, pues para determinado año consiguen menos embajadores de marca.

Tabla 5.1

Postulaciones de 2012 a 2014

\begin{tabular}{|c|c|c|c|}
\hline Año & $\begin{array}{c}\text { Postulaciones } \\
\text { terminadas }\end{array}$ & Seleccionados & PEP \\
\hline 2012 & 1100 & 65 & 61 \\
\hline 2013 & 1082 & 65 & 55 \\
\hline 2014 & 1471 & 84 & 37 \\
\hline
\end{tabular}

Fuente: elaboración propia; datos obtenidos de Enseña Perú hasta el momento de la investigación.

Tener un elevado número de postulaciones implica que la comunicación externa está siendo correcta y persuasiva, pues el posicionamiento está mejor definido,

\footnotetext{
${ }^{24}$ Pasó de ser un programa en el que se iba a enseñar y ser profesor, a ser un programa de liderazgo.

${ }^{25}$ Entrevista con Franco Mosso (Director Ejecutivo).
} 
así como los objetivos. Se notó el incremento entre 2013 y 2014 respecto al número de personas que se inscribieron. Por lo tanto, están atrayendo mayores talentos y, a su vez, deberían estar atrayendo más financiamientos, pues sin ello no pueden seleccionar a más postulantes.

Sin embargo, no basta con atraer muchos talentos, sino retenerlos. La percepción en relación a si es un equipo y todos están "juntos en lo mismo" no es pareja. Esto se explica porque las áreas del Staff no están engranadas, como se demostró, y los PEP se sienten alejados. Si no se sienten unidos, difícilmente van a poder lograr los objetivos de la organización.

El problema evidenciado tiene una consecuencia. Si estando dentro de la misma organización no se sienten integrados, cuando pasen a ser Alumnis se sentirán en menor grado aun. Se recuerda que el objetivo final de la organización gira en torno a la puesta en marcha de propuestas de los Alumnis desde sus puestos de trabajo para la mejora de la educación, por ello la importancia de mantenerse en red. 


\section{DISCUSIONES}

Se inició la investigación partiendo de la premisa que las organizaciones del tercer sector evidencian problemas de comunicación interna, lo que ocasiona un falta de fortalecimiento en su cultura. Es así como, en el caso estudiado, la comunicación interna es deficiente. No se halló una estrategia de comunicación interna, realizan actividades y tareas que son ejecutadas y podrían ser parte de una estrategia siempre y cuando exista un lineamiento. Asimismo, se evidenció que la comunicación en cada área es mejor que la que se da entre áreas; además, no existe una comunicación en cascada. Es importante este proceso ya que, para la Asociación Española de Dirección y Desarrollo de Personas (AEDIPE, 2011), el fundamento de comunicación interna es que uno de los métodos más importantes para transmitir la información es la comunicación en cascada.

El problema hallado respecto a que los mensajes no llegan a los diferentes puntos está también relacionado con uno no comunicacional: el compromiso de los colaboradores. El público estudiado considera que no siempre trabaja en equipo y coordinados, por lo que la comunicación se dificulta. Como mencionan Balas (2011) y La Porte (2001), una de las principales causas a esta deficiencia se explica por la inexistencia de un área que se encargue de gestionar la comunicación interna y lo que a su vez conlleva a que no haya canales de comunicación adecuados ni bien empleados. En contraposición, Cabanas \& Soriano (2014) comentan que la comunicación interna puede ser independiente y no tener una propia área siempre y cuando se base en los objetivos estratégicos. Por ello, sabiendo que las OTS cuentan con bajo presupuesto, deberían contar con un solo responsable sin la necesidad de establecer un departamento. 
Balas (2011) menciona que las organizaciones no se comunican eficazmente porque la perciben como un problema. Las últimas se centran en la difusión promocional, mediática y basada en búsqueda de recursos; es decir, la comunicación interna no es tomada en cuenta, porque consideran que la externa tiene más peso. Enseña Perú se centra en reclutar el mayor número de profesionales y encontrar donantes que permitan que la organización funcione; pero, como se ha evidenciado, no cuenta con estrategias de comunicación interna establecidas.

Lo mencionado, para este caso, confronta la investigación de Durán y Fernández (2010), pues ellos señalan que las organizaciones no tienen la capacidad para transmitir a la sociedad problemas importantes o no se conoce sobre las mismas y se conoce mal y tienen problemas al proyectar la realidad asociativa. Aquí, si bien no se trató de estudiar la comunicación externa, mediante las entrevistas y resultados se encontró que se ha logrado posicionar la organización y reclutar a más profesionales. En lo que aún hay deficiencia y donde se debe trabajar es en mantener el discurso que generan dentro de la organización, a largo plazo. Esto solo se puede lograr viviendo y transmitiendo la cultura, con ayuda de la comunicación. Se trata, como dicen Duran y Fernández, de mantener una comunicación integral ${ }^{26}$.

Para lograr una comunicación integral, se debe conocer a los stakeholders, más aún cuando la organización cuenta con tres públicos distintos. A lo largo de la investigación, se demostró que las percepciones de cada uno respecto a la asociación son diferentes, lo que implica que la comunicación y los mensajes no llegan por igual. Por ello, es necesario conocer cada uno de los perfiles y diseñar una estrategia para cada uno con la finalidad de fortalecer la cultura y mejorar la comunicación. Si bien en la mayoría de organizaciones se trabaja con el Staff y los voluntarios, estos últimos son miembros no estables. La alta rotatividad hace que se les trate de manera diferente (Etkin, 2012, p. 71). Ellos son clave para promover las acciones de la organización, por lo que se debe trabajar insistentemente. Los PEP no son voluntarios, pero son miembros

\footnotetext{
26 "Una forma de entender la comunicación en una organización tanto en una dimesion externa como interna, con el fin de generar una imagen publica favorable a los objetivos de las organización" (Duran y Fernández, 2010).
} 
que están solo por dos años; por ello, la comunicación hacia este grupo debe ser específica e intensa.

"Olvidar que en la empresa conviven distintos públicos y no segmentar la comunicación para que sea relevante y útil para ellos" es uno de los veinte pecados que la consultora Apoyo Comunicación desarrolla sobre la comunicación. En este caso y para todas las organizaciones del sector, se debe segmentar la comunicación, pues los tres públicos están en espacios físicos diferentes, tienen distintas responsabilidades y por ello es que los PEP sienten al back office alejado, pues no se les comunica adecuadamente lo que pasa en la organización.

La comunicación con los PEP es trascendental respecto a cómo lograr que se identifiquen y comprometan con la organización. Son los potenciales Alumnis que estarán fuera de la asociación y son la fuerza de trabajo para que la visión pueda cumplirse. Deben vivir la cultura para que, cuando pasen a ser parte de la red Alumnis, sigan pensando como agentes de cambio y logren el cambio en la educación. Ellos son actores sensibles que están dentro y fuera de la organización y es así como se debe entenderlos; son portavoces de la organización (Etkin, 2012). Como menciona la Asociación Española de Dirección y Desarrollo de Persona (AEDIPE, 2011), la comunicación interna debe gestionarse pensando que uno de sus objetivos es retener a todas las personas que son decisivas para lograr el éxito (aquí los Alumnis).

El ADN de la organización —es decir, su identidad- no está totalmente definida. Si no lo está, la cultura a su vez tampoco es sólida y difícilmente estará presente en cada colaborador. Lo que sí se puede rescatar es que ya se definen como un programa de liderazgo para profesionales. No se trata solo de enseñar a poblaciones vulnerables, sino que el propio PEP sea un agente de cambio luego de vivir la experiencia. Este cambio ha sido reciente tanto para el Staff como para los profesionales que se inscribían con la finalidad de enseñar.

Lo señalado ilustra la teoría de Rodríguez y Quesada (2007), ya que este tipo de organizaciones muestra el paso del cumplimiento de la misión a la de intervención. Ya no se busca paliar, sino ocuparse de la prevención potenciando "agentes de cambio" o posteriormente Alumnis que, desde donde estén, hagan cambios en la educación.

Enseña Perú es una organización que se define por el liderazgo; por lo tanto, el líder debería ser una figura que busque transmitir esto y que sea reconocida por sus 
miembros. Sin embargo, no todos los colaboradores coinciden. Para el Staff, su líder es el Director del Programa, mientras que los PEP identifican más a los coordinadores como sus líderes. Cabe mencionar que, cuando hablamos de este, no necesariamente se debe hacer referencia al representante máximo de la organización, sino a los funcionarios que encabezan equipos de trabajo (Sheen, 2016). En cualquiera de los casos, todos deben estar alineados y transmitir la cultura en el día a día. Debería ser la cabeza de la organización que irradie sobre los jefes-coordinadores y a su vez a los PEP. Sin embargo, al no haber comunicación en cascada, se dificulta el proceso.

"No formar ni identificar a los líderes formales y naturales de la empresa" es otro de los pecados que Apoyo Comunicaciones identifica. ¿Por qué es tan importante el líder y el liderazgo en una organización como esta, donde además se habla todo el tiempo de liderazgo? Alejandro Formanchuk (2011) dice que es el líder de la organización quien lleva a cabo las prácticas que marcan la cultura y esta misma la plataforma que permite construir marcas poderosas para los empleados. Cada cultura genera experiencias distintas que impactan y provocan emociones diversas. Es a partir de estas experiencias que los colaboradores se sienten parte de la organización y se convierten en embajadores de marca, gracias al liderazgo de sus líderes.

El problema hallado es que, al no haber líderes idealizados e identificados, no hay quien defina y transmita la cultura. Por ello es que se encuentran diferencias marcadas en cómo los diferentes públicos perciben la organización.

Una identidad que no está definida, trae consigo una serie de consecuencias respecto a los mensajes que la organización sostiene hacia sus stakeholders. Si la identidad no está determinada, la cultura tampoco lo estará. Sin ninguna de estas, la comunicación interna funcionará. Como consecuencia es que una comunicación deficiente implica una cultura organizacional no sólida.

Es decir que no existe una especie de "héroe" o un "guardián de la cultura"27 que vele por preservar y transmitir la cultura. En efecto, las diferentes áreas tienen distintas formas de trabajar; pues, como se halló, cada jefe trata de que su equipo se

27 Término utilizado en la organización J\&V Resguardo-Liderman. La referencia es La oreja en el piso, cuyo autor es Javier Calvo Pérez, líder de esta organización. 
involucre e integre a su manera. El riesgo de esto, como se pudo apreciar, es que cada equipo funcionará sobre la base de la proactividad de ese líder. Así, se encontraron diferencias marcadas entre los grupos. Si el líder no es proactivo o no tiene el mismo grado que los de otra área, ese determinado grupo se verá afectado.

Si bien no existe un "guardián de la cultura", se identificó que existen actividades y ritos que se realizan y permiten demostrar que algunos elementos de la identidad, como los valores, se han podido interiorizar. Sin embargo, estas actividades, una vez más, no son institucionalizadas ni establecidas para todos por no existir una estrategia. Se evidenció que hay áreas que se desempeñan mejor porque realizan actividades de integración. Los gerentes son conscientes de ello y por esta razón es que se debería formalizar, pues son elementos claves que fortalecen una cultura y permiten que los colaboradores se sientan parte de la misma.

Actividades como "la búsqueda del tesoro", la premiación de los valores y el mismo Instituto de Verano ayudan a fortalecer la cultura; pues, como mencionan Cabanas \& Soriano (2014), es apostar por procesos de identidad argumentados y dialogados en los que el empleado tiene que ser parte activa al conocer, interpretar y adoptar los valores y comportamientos. Esto permite que haya orgullo de pertenencia y fomenta la colaboración dentro del proceso del employer branding.

Los dos años en Enseña Perú son claves para lograr un desempeño y compromiso con la organización en los siguientes años, cuando los Alumnis estén en el campo, pues de eso depende lograr la visión. Por ello, la cultura debe fortalecerse. Así, cuando culminen con el programa, se lleven consigo la marca de Enseña Perú impregnada en ellos y sean embajadores de la misma. El INVE es por sí mismo una experiencia única, pero es necesario fortalecer estas vivencias a lo largo del programa y no solo al inicio.

El Staff es una fuerza de trabajo importante, sin la cual no se podría lograr la operación. Por ello, para este grupo es necesario realizar actividades internas que fomenten la unión y el trabajo en equipo. Además, el grado de compromiso refleja que son muy pocos los que trabajarían como voluntarios; es decir, sin ser remunerados. Como mencionan Cabanas \& Soriano (2014), el salario no es el único factor motivacional que retiene el talento. Lograr que los colaboradores se sientan parte de la 
cultura, apreciados y valorados, aumenta la competitividad y eficacia. En este sentido, la comunicación interna es un pilar para lograr la motivación y la integración.

Es por ello que la organización debe hacerlos sentir muy especiales e importantes para lograr que su compromiso sea más fuerte y no dependa de una remuneración, pero sí de un salario emocional que los motive, comprometa y enganche a lograr la visión. Si se logra una mejor comunicación, se transmitirá una mejor cultura y así conseguirán colaboradores más comprometidos y una buena reputación. Como menciona la Asociación Española de Dirección y Desarrollo de Personas:

La reputación de la empresa comienza por el propio trabajador [...] cuando cuentas con empleados comprometidos, estas consiguiendo embajadores que transmiten una buena imagen de la compañía y ayudan en la atracción del talento (AEDIPE, 2011, p. 57).

Finalmente, otro problema encontrado es respecto a la cohesión como equipo. Menos de la mitad de los PEP dijo que siempre se sienten juntos, lo cual trae consecuencias en relación al objetivo; pues, cuando ellos pasen a ser parte de la red de Alumnis, se sentirán aún más desligados y se recuerda que ellos son los potenciales agentes de cambio para lograr una educación de calidad. Por ello, son los PEP los más unidos y comprometidos deben sentirse con la organización. La experiencia en Enseña Perú es clave para lograr un desempeño y compromiso con la organización en los siguientes años.

He aquí el desafío del que hablaba La Porte (2005) acerca de la construcción del "trabajo en equipo y el trabajo en red". Enseña Perú ha logrado, según su modelo, crear una red que permita mapear a todos los Alumnis convertidos en líderes luego de haber pasado por los dos años, para que sean los que marquen el cambio en la educación del país. Asimismo, esta misma red permite ocuparse de la prevención, como señalaban Rodríguez y Quesada. Los Alumnis son las posibles alianzas estratégicas que necesita la organización. Se trata de incorporar conocimiento profesional a la gestión. Trabajar de la mano con el sector privado, que ya lo viene haciendo; pero no solo como donante, sino como un estratega. Sin embargo, para que la red se mantenga y funcione, una vez más es necesario que la cultura organizacional se fortalezca, más aun cuando mencionaron que no se sentían cohesionados. 
El aporte que estas páginas pueden contribuir a la misma organización y a la comunidad académica es que, si bien la comunicación externa ha servido para aumentar el número de postulaciones, la comunicación interna y la cultura son dos factores necesarios para que organizaciones del tercer sector tengan éxito y mejor funcionamiento, pues gestionarlas marca una diferencia, más aun en este caso que cuentan con una ventaja diferencial (como es el programa y la remuneración). Una vez más se evidencia la debilidad que tienen muchas organizaciones del tercer sector. La cultura, en este caso, no es sólida y la comunicación interna tiene muchas trabas, lo que obstaculiza llegar a su meta principal.

El tercer sector necesita de las empresas privadas, tanto en donaciones como en estrategias, como lo estudiaron Rodríguez y Quezada (2007), evidenciando que este tipo de organizaciones necesita adoptar modelos de gestión del sector empresarial. Así, conseguir la contribución de las empresas o instituciones es como estar en el mercado, donde empresas compiten para tener mayor número de consumidores. Aquí, las organizaciones buscan financiamiento para poder gestionar los proyectos. Así, la imagen corporativa es fundamental para ello. El ideal de una organización debe ser el autosostenimiento que se puede lograr en función de un valor intangible como el de la confianza, es decir, la reputación. Costa (2003) dice que la imagen de la organización es un fenómeno al mismo tiempo de percepciones y de experiencias por parte de los públicos; de comunicaciones, relaciones e interacciones entre ellos y la empresa.

El reto de Enseña Perú está en hacer de los Alumnis los mejores embajadores de marca y para ello se debe comenzar con los PEP. La remuneración es una ventaja diferencial; pero deben potenciar el salario emocional, el reconocimiento, que se les haga sentir el protagonismo de cada colaborador.

Se sabe que en ocasiones disminuyeron el número de seleccionados por falta de fondos, perjudicando sus metas. Una de las maneras de atraer más fondos y donde recae la importancia de esta investigación es trabajando en los intangibles como la reputación y la cultura, además de la comunicación interna, todos necesarios para generar una buena imagen. Son los trabajadores los portavoces externos de la organización de quienes más se fían en su entorno, porque se supone que disponen de la información directa y, por lo tanto, más fiable y segura que se pueda obtener (AEDIPE, 2011). 


\section{RECOMENDACIONES}

\begin{tabular}{|c|c|}
\hline Hallazgos & tontes a \\
\hline $\begin{array}{l}\text { Comunicación interna deficiente: } \\
\text { - No existe comunicación en cascada. } \\
\text { - Mala y poca comunicación entre las } \\
\text { diferentes áreas. } \\
\text { - No hay canales apropiados para los } \\
\text { distintos públicos. } \\
\text { - Los PEP no se sienten lo } \\
\text { suficientemente informados sobre lo } \\
\text { que pasa en la organización. }\end{array}$ & $\begin{array}{l}\text { La comunicación debe plantearse bajo el } \\
\text { paradigma de: saber, sentir y hacer } \\
\text { (Cabanas \& Custodia, 2014). } \\
\text { Los tres públicos deben estar involucrados } \\
\text { en las acciones de comunicación interna } \\
\text { que se tomen. } \\
\text { - El Staff debe trabajar y sentir en } \\
\text { mayor grado que son un equipo. Por } \\
\text { ello, es necesario potenciar los canales } \\
\text { de comunicación (creando un intranet, } \\
\text { administrando constantemente los } \\
\text { canales) e institucionalizar tardes de } \\
\text { integración para fomentar la cultura y } \\
\text { el compañerismo, entre el Staff, PEP y } \\
\text { Alumnis, con la finalidad de que el } \\
\text { primer grupo se sienta más cerca y } \\
\text { poder mantener la red. } \\
\text { Establecer las reuniones con } \\
\text { periodicidad entre las distintas } \\
\text { jerarquías para que la comunicación } \\
\text { sea en cascada y llegue a oídos de } \\
\text { todo el Staff y a su vez a los PEP. De }\end{array}$ \\
\hline
\end{tabular}




\begin{tabular}{|c|c|}
\hline & $\begin{array}{l}\text { esta manera, también se van a } \\
\text { estandarizar los procesos y se evita la } \\
\text { proactividad y diferencias entre cada } \\
\text { equipo. }\end{array}$ \\
\hline $\begin{array}{l}\text { No existe personal que gestione la } \\
\text { comunicación interna. }\end{array}$ & $\begin{array}{l}\text { Crear en lo posible un área o designar a } \\
\text { un encargado que gestione la } \\
\text { comunicación, alineada a la estrategia de } \\
\text { la organización. El encargado deberá } \\
\text { ocuparse de: } \\
\text { - Diseñar un plan de comunicación } \\
\text { interna anual. } \\
\text { - Gestionar los diferentes canales de } \\
\text { comunicación según los diferentes } \\
\text { públicos, generando contenido } \\
\text { (mailing, generar y administrar una } \\
\text { plataforma -intranet-, foros y/o } \\
\text { chat, vitrinas con mensajes en la } \\
\text { oficina principal, establecer un } \\
\text { calendario de reuniones). } \\
\text { Crear y establecer las actividades de } \\
\text { integración en coordinación con la } \\
\text { dirección ejecutiva (institucionalizar } \\
\text { las actividades de reconocimientos y } \\
\text { logros). } \\
\text { Liderar los encuentros de integración. } \\
\text { Monitorear el uso de canales y medir } \\
\text { la eficiencia de la comunicación } \\
\text { mediante indicadores. }\end{array}$ \\
\hline $\begin{array}{l}\text { No segmentan al público interno para } \\
\text { realizar la comunicación, debido a que no } \\
\text { existe una estrategia interna. }\end{array}$ & $\begin{array}{l}\text { Es necesario diferenciar tanto canales de } \\
\text { comunicación como los grupos de } \\
\text { colaboradores para que la comunicación }\end{array}$ \\
\hline
\end{tabular}




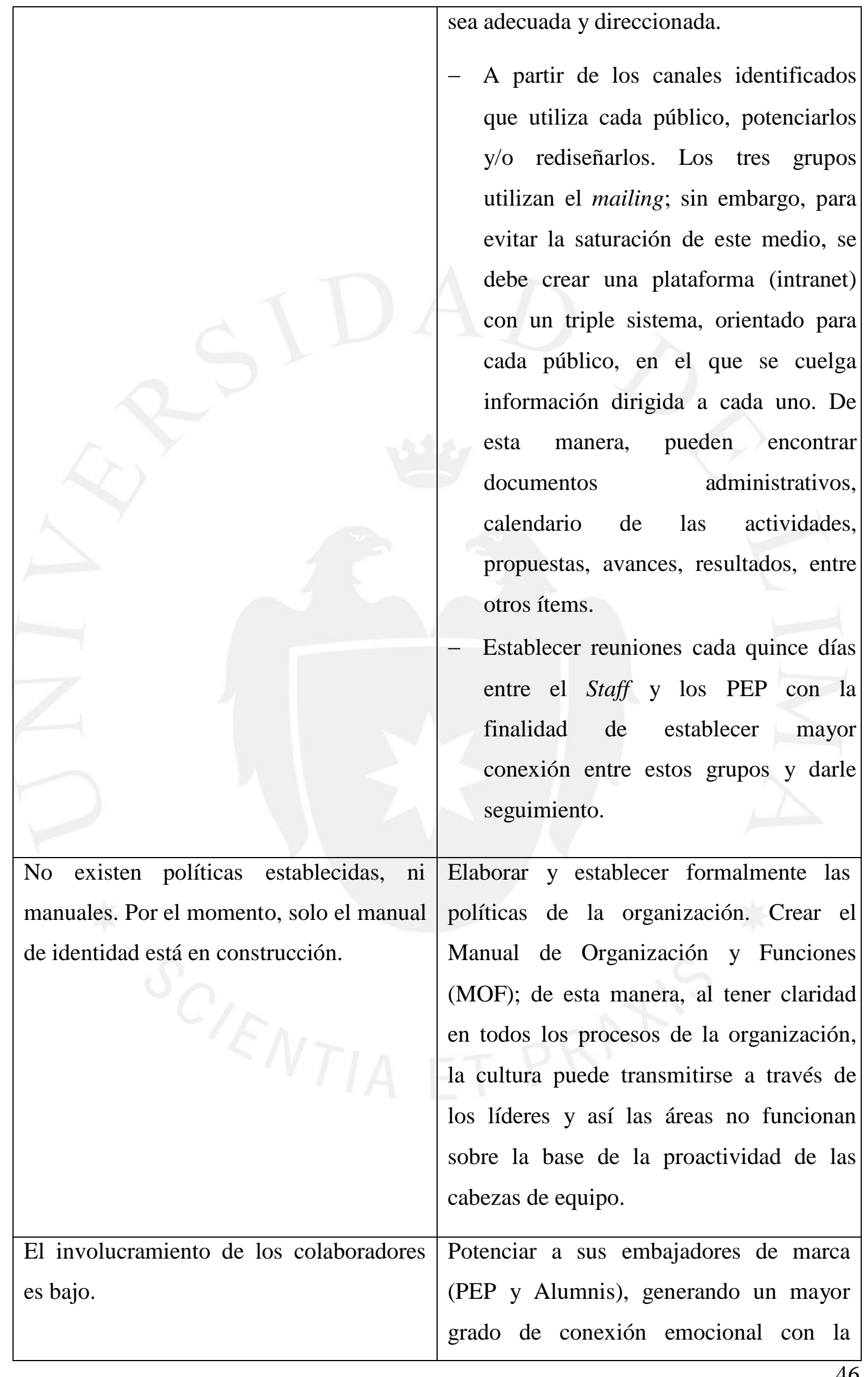




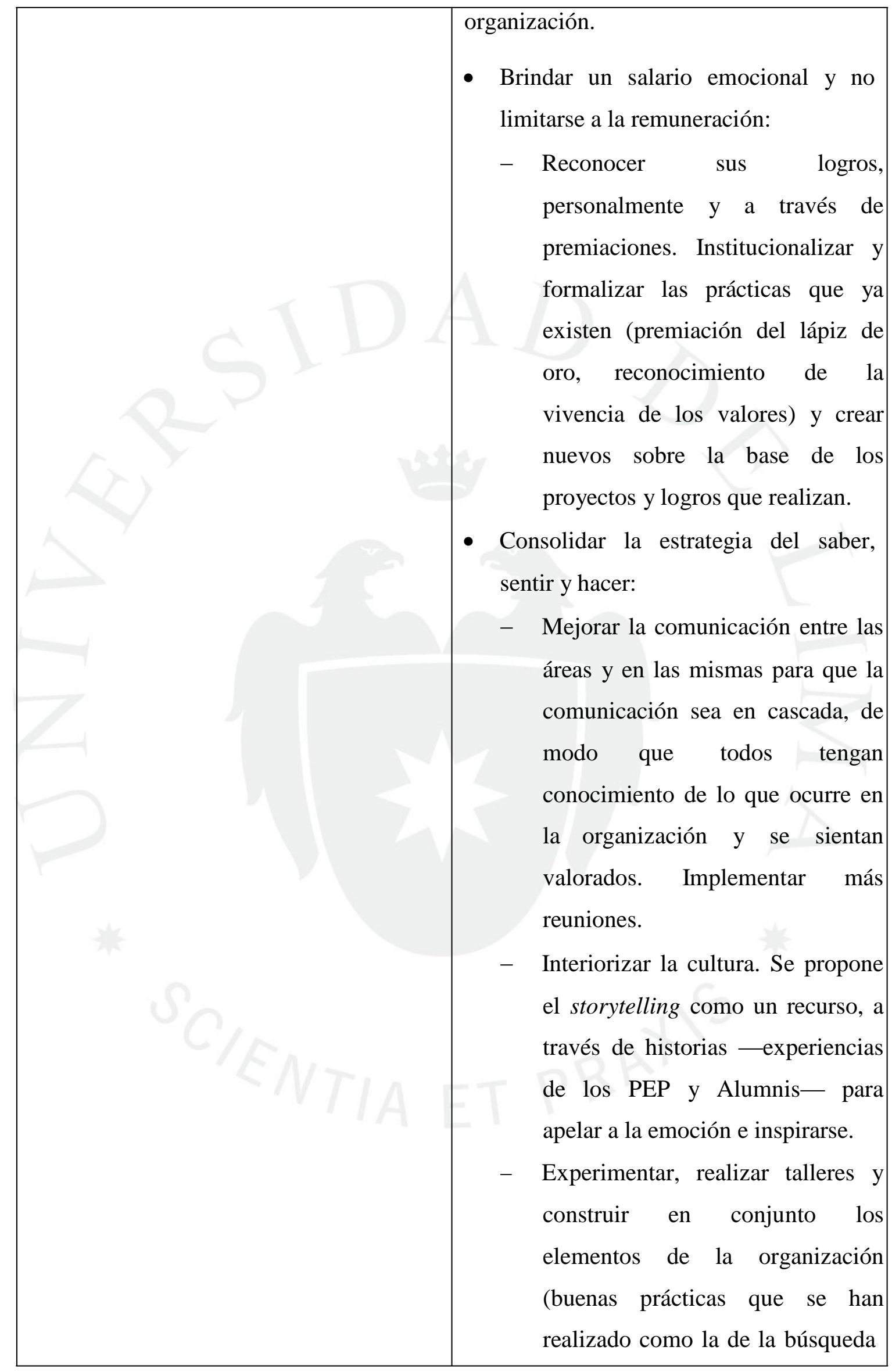




\begin{tabular}{|c|c|}
\hline & \\
\hline & $\begin{array}{l}\text { Aumentar y realizar más encuentros entre } \\
\text { el líder y sus colaboradores. } \\
\text { _ } \text { Mayor presencia en las escuelas, dos } \\
\text { veces al mes. } \\
\text { - Presenciar y dirigir los encuentros de } \\
\text { integración. } \\
\text { Crear un personaje (como un guardián de } \\
\text { la cultura) que permita irradiar y dotar a } \\
\text { los otros líderes de la Cultura Enseña } \\
\text { Perú. }\end{array}$ \\
\hline $\begin{array}{l}\text { Cultivar la red de Alumnis, para llegar a } \\
\text { la meta educativa, de Enseña Perú y lograr } \\
\text { una mejora en la educación. }\end{array}$ & $\begin{array}{l}\text { Potenciar la red. } \\
\text { - } \text { Mantener a los Alumnis cohesionados. } \\
\text { Crear más encuentros donde se } \\
\text { exponga lo que realizan los Alumnis } \\
\text { desde que egresan del programa. } \\
\text { - } \text { Galardones para este grupo. } \\
\text { - Concursos e incentivos relacionados } \\
\text { al trabajo que realizan desde su } \\
\text { puesto. } \\
\text { Conectar a Enseña Perú con cada } \\
\text { institución con la que los Alumnis } \\
\text { trabajan, con la finalidad de trabajar } \\
\text { en conjunto con estrategas, generar } \\
\text { propuestas, } \\
\text { financiamientos. }\end{array}$ \\
\hline \multicolumn{2}{|c|}{$\begin{array}{l}\text { En conclusión, se debe gestionar el employer branding para obtener una reputación } \\
\text { interna positiva, que se puede lograr tomando en cuenta estas consideraciones y que se } \\
\text { verá reflejada hacia sus stakeholders externos. Si se gana reputación, aumenta el nivel } \\
\text { de confianza y, por consecuente, el número de PEP y Alumnis se elevará, así como los } \\
\text { gestores y donantes, logrando que en, } 2032,8 \text { de cada } 10 \text { niños reciban una mejor }\end{array}$} \\
\hline
\end{tabular}


educaci6n. 


\section{BIBLIOGRAFÍA}

Aguilar, A. (2009). El diagnóstico de la cutlura organizacional o las culturas de la cultura. Global Media Journal Edición Iberoamericana, 67-81.

Asociación Española de Dirección y Desarrollo de Personas (AEDIPE) (2011). Comunicación Interna en la Empresa. Valencia: Wolters Kluwer España.

Balas, M. (2011). La gestión de la comunicación en el Tercer Sector. Madrid: ESIC.

Cabanas, C., \& A. Soriano (2014). Comunicar para transformar. Madrid: Lid Pub Inc.

Carreras, E. (2013). Reputación corporativa. Bogotá: Ediciones de la U.

Costa, J. (2003). Imagen Corporativa en el siglo XXI. Buenos Aires: La Crujía.

Costa, J. (2011). El ADN del DirCom. Barcelona: Costa Punto Com.

Durán, P., \& M. B. Fernandéz (2010). La comunicación en las organizaciones del tercer sector. Revista Latina de Comunicación Social, 595-603.

Etkin, E. (2012). Comunicación para organizaciones sociales. Buenos Aires: La Crujía.

Formanchuk, A. (2011). Branding Interno: Una trama inteligente. Buenos Aires: Formanchuk \& Asociados.

Ganga, F., B. Juan \& A. Máximo (2010). Aproximación teórica a las organizaciones del tercer sector. Espacio Abierto. Cuaderno Venezolano de Sociología, 51-75.

La Porte, J. M. (2001). Entusiasmar a la propia institución. Madrid: Eunsa.

La Porte, J. M. (2005). Potencialidad creativa de la comunicación interna en el tercer sector. Potencialidad creativa de la comunicación interna en el tercer sector. Buenos Aires: Comunia. 
Losada, J. C. (2004). Gestión de la comunicación en las organizaciones: comunicación interna, corporativa y de marketing. Barcelona: Ariel.

Munera, P., \& U. Sanchez (2003). Comunicación empresarial una mirada corporativa. Medellín: Zualuaga.

Pérez-Rosas, A. (2015). La cultura organizacional como ventaja competitiva en el mundo de los negocios. Lima: Instituto Desarrollo Intelectual (IDI).

Pintado, T., \& H. Sánchez (2013). Imagen Corporativa: Influencia en la gestión empresarial. Madrid: ESIC.

Portocarrero, F. \& otros (2001). El tercer sector en el Perú: una aproximación cuantitativa. Lima: CIUP.

Rodriguez, D., \& S. Quezada (2007). Cultura en las organizaciones del tercer sector chileno. Revista Española del Tercer Sector, 121-151.

Sheen, R. (2016). La cultura organizacional y su impacto en la gestión empresarial. Lima: Universidad de Lima.

Villafañe, J. (2013). La buena empresa: propuesta para una teoría de la reputación corporativa. Madrid: Pearson. 
ANEXOS 
ANEXO 1: CAMBIO DE LOGOTIPO
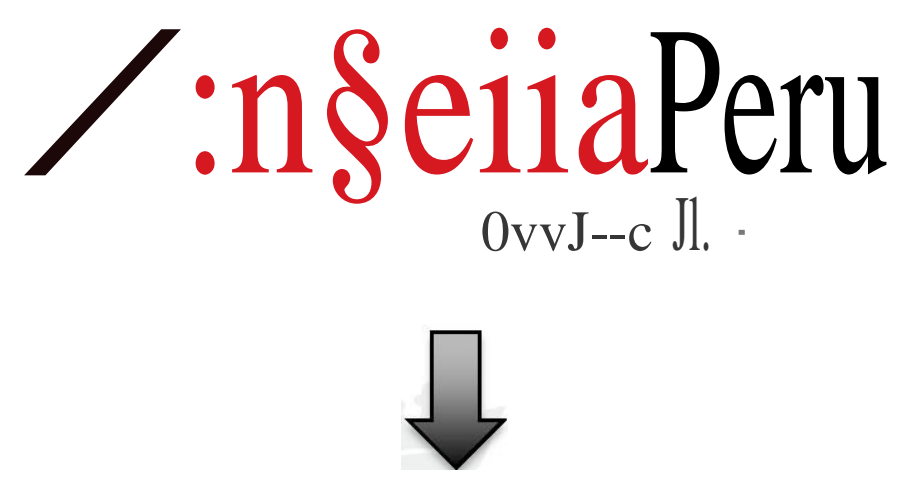

enseñe 


\section{ANEXO 2: DECLARACION DE POSICIONAMIENTO \\ CREADO MEDIANTE EL JUEGO DE LA BUSQUEDA}

\section{DEL TESORO}

\section{Declaraci6n de posicionamiento}

Creemos en el poder de Ia educaci6n.

Confiamos en el potencial de los peruanos. Queremos un pais donde todos tenga mos Ia oportunidad

de realizar nuestro prop6sito, de alcanzar nuestros suefios.

Por eso, atraemos talento profesional para que trabajen porIa educaci6n.

Por eso, forma mos lideres que se proponen ir, siempre, mas alia de sus propios logros.

Personas apasionadas por transformar su entorno y ayudar a los demas a hacer lo mismo.

\section{Declaraci6n de \\ posicionamiento}

Por eso, impulsamos un movimien to liderado por estos profesionales para que contribuyan, desde donde esten, a ese gran sueilo.

Nuestra vision es inmensamen te simple: 8 de cada 10 ninos peruanas recibiran una educaci6n de excelencia en e/2032. 


\section{ANEXO 3: ENCUESTA APLICADA A LOS TRES}

\section{PÚBLICOS OBJETIVOS}

\section{Encuesta anónima, con fines académicos-Universidad de Lima-Facultad de Comunicaciones.}

Género: F M Edad: 20 a 30- 31 a 40- 41 a 50- 50 a más

Rol en Enseña: Staff- PEP - Alumni

De acuerdo a las frases, marque usted la respuesta con la que más se identifique.

1. Siente usted que en Enseña Perú la misión y visión están definidas. (Siendo 5 muy definida y 1 no definida)

\begin{tabular}{|l|l|l|l|l|}
\hline 5 & 4 & 3 & 2 & 1 \\
\hline
\end{tabular}

\begin{tabular}{|l|l|l|l|l|l|}
\hline & Siempre & $\begin{array}{c}\text { Con } \\
\text { frecuencia }\end{array}$ & $\begin{array}{c}\text { A } \\
\text { veces }\end{array}$ & $\begin{array}{c}\text { Casi } \\
\text { nunca }\end{array}$ & Nunca \\
\hline $\begin{array}{l}\text { 2. Llevo conmigo la misión y la visión } \\
\text { a diario en mi trabajo. }\end{array}$ & & & & & \\
\hline $\begin{array}{l}\text { 3. En Enseña Perú todos estamos } \\
\text { interesados en cumplir con nuestros } \\
\text { objetivos. }\end{array}$ & & & & & \\
\hline $\begin{array}{l}\text { 4. Cuando requiero apoyo y lo solicito } \\
\text { me lo proporcionan en la medida de lo } \\
\text { posible rápido. }\end{array}$ & & & & & \\
\hline $\begin{array}{l}\text { 5. Mi superior inmediato está } \\
\text { disponible cuando lo requiero. }\end{array}$ & & & & & \\
\hline
\end{tabular}




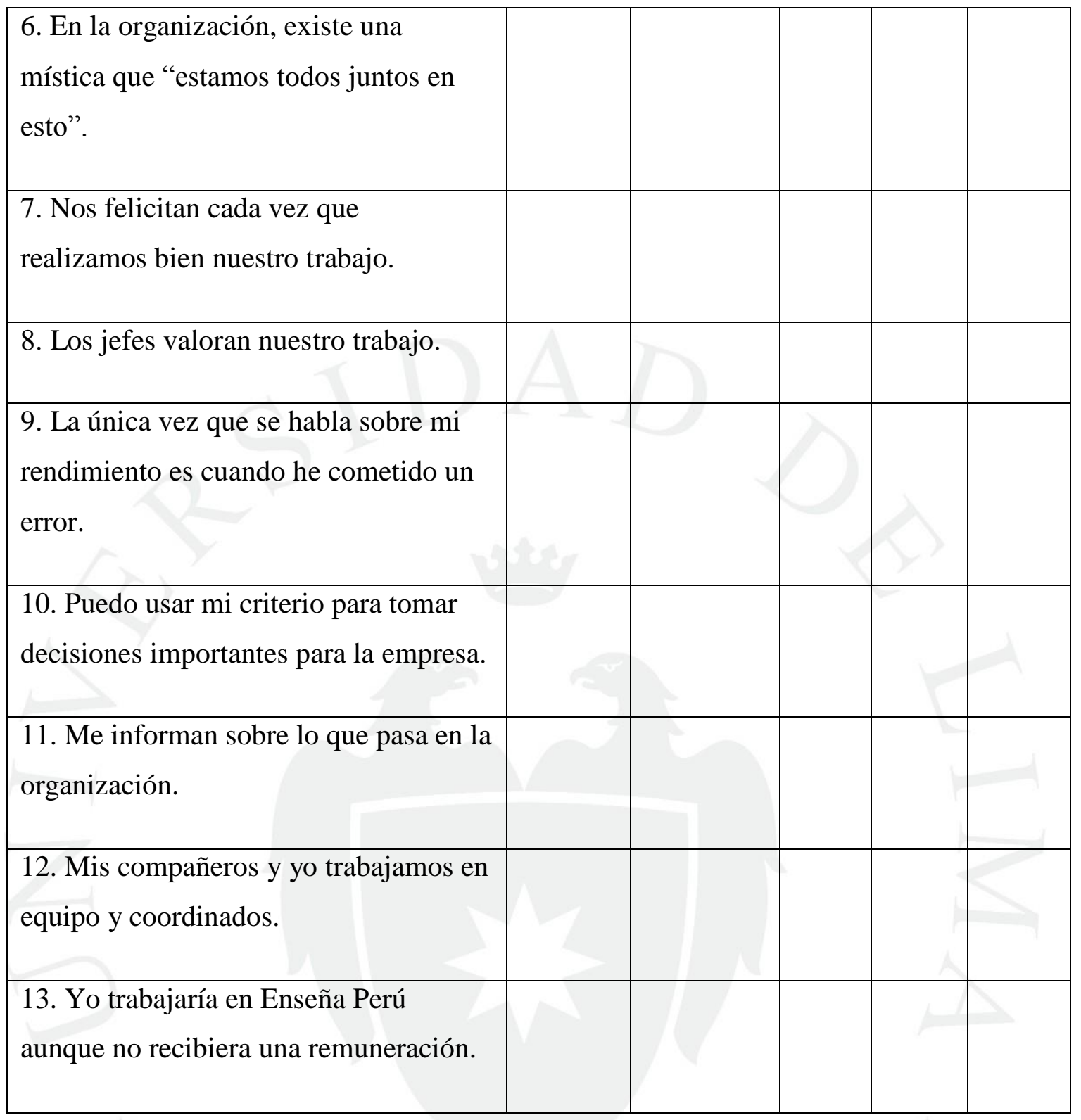

14. Mi propósito en Enseña Perú es:

a) Quiero vivir la experiencia de ser profesor y enseñarle a niños en situación de pobreza.

b) Quiero ayudar a que más niños tengan acceso a la educación.

c) Quiero ser un líder y buscar soluciones a los problemas del país.

d) Quiero crecer profesionalmente.

e) Quiero vivir la experiencia de trabajar en una organización sin fines de lucro.

f) Quiero trabajar en una organización reconocida.

g) Otros:

15. Cuál de los siguientes valores representa a Enseña Perú (elige máximo 4)

a) Humildad

b) Perseverancia 

c) Honestidad
d) Respeto
e) Confianza
f) Solidaridad
g) Sentido de posibilidad
h) Otros:

16. El objetivo en Enseña Perú es:

a) Ser un movimiento liderado por "agentes de cambio".

b) Reducir el analfabetismo.

c) Brindar una educación de calidad a niños vulnerables.

d) Otro:

17. ¿Cómo calificaría el ambiente interno de Enseña Perú?

\begin{tabular}{|l|l|l|l|l|l|}
\hline Muy bueno & Bueno & Regular & Malo & Muy Malo & No opina \\
\hline
\end{tabular}

18. La comunicación dentro de mi área es:

\begin{tabular}{|l|l|l|l|l|l|}
\hline Muy buena & Buena & Regular & Mala & Muy Mala & No opina \\
\hline
\end{tabular}

Porque.

19. La comunicación entre las diferentes áreas es:

\begin{tabular}{|l|c|c|c|c|c|}
\hline Muy buena & Buena & Regular & Mala & Muy Mala & No opina \\
\hline
\end{tabular}

Porque.

20. ¿Cuáles son los canales que utiliza para enterarse de lo que pasa en la organización? (puede marcar varias alternativas)

\begin{tabular}{|l|l|l|l|l|l|l|}
\hline 1.Mail & 2. & 3.Teléfono- & 4. Redes & 5. Videos & 6. Mis & 7. Otros \\
& Reuniones & skype & $\begin{array}{l}\text { sociales } \\
\text { (facebook,twitte } \\
\text { institucionales }\end{array}$ & & compañeros & \\
& & & & & & \\
& & & & & & \\
\hline
\end{tabular}


21. ¿Ha recibido capacitaciones de la organización?

22. ¿Cree que son útiles?

23. ¿Cree que se necesiten más capacitaciones?
a) Sí
b) $\mathrm{No}$

\begin{tabular}{|l|l|}
\hline a) Sí & b) No \\
\hline
\end{tabular}
a) Sí
b) No

24. Si respondió la anterior, en qué áreas cree que se requerirían

25. ¿Cómo cree usted que es su jefe en Enseña Perú? (marque 4 como máximo)

\begin{tabular}{|l|l|l|l|l|l|l|l|l|}
\hline 1.alentador & 2.empático & 3.líder & 4.flexible & 5. estricto & $\begin{array}{l}\text { 6.sabe } \\
\text { escuchar }\end{array}$ & 7.distante & 8.integrador & 9. otros \\
\hline
\end{tabular}

26. ¿Cómo es la gente en Enseña Perú? (marque máximo 3)

\begin{tabular}{|l|l|l|l|l|l|l|}
\hline 1.Divertida & 2.amigable & 3.reservada & 4.seria & 5.responsable & 6. confiable & 7. otros \\
\hline
\end{tabular}

27. Si Enseña Perú fuera una persona como sería, descríbala. Por ejemplo, características como género, edad, características físicas, personalidad, elementos que lleva consigo, que lo definen, etc. 


\section{ANEXO 4: GUÍA DE PREGUNTAS PARA LAS}

\section{ENTREVISTAS AL STAFF}

Funciones que desarrolla en su área.

Objetivos de la organización

Respecto a los PEP y la organización.

Objetivos de corto y largo plazo.

Metas para fin de año, ¿cómo logran estas metas?

¿Cuál es el perfil que debe tener un PEP? ¿Cómo es el proceso de selección?

\section{Comunicación}

¿Cómo es la comunicación dentro de la organización? ¿A través de qué canales se da?

Herramientas que utilizan para la comunicación.

¿Quiénes toman las decisiones?

¿Cuánta gente tiene a tu cargo? ¿Cómo se comunicas con ellos? ¿A través de qué medios? (herramientas) ¿Qué tipo de material, videos, folletos...?

El entorno digital, ¿cómo lo manejan?

¿A quién le rinde cuentas? ¿Cómo se da la comunicación entre jefe y subordinado?

¿Cada cuánto tiempo tienen reuniones? (Integrantes)

¿Cada cuánto tiempo realizan programas de integración? ¿Quiénes asisten? ¿Qué hacen en estas jornadas?

¿Realizan reuniones fuera del trabajo? ¿En qué ocasiones?

$\underline{\text { Identidad y cultura }}$

¿Por qué decidieron hacer un cambio de logo (identidad visual)? ¿Cuándo lo realizaron?

- Objetivos

¿Qué transmite este nuevo logo?

Tipo de vestimenta para los PEP. 
¿Qué significa Enseña Perú? ¿Cuáles son los principales valores? En una palabra, ¿qué es Enseña Perú? ¿Cómo define Enseña Perú?

¿Cómo definiría un colaborador de Enseña Perú?

¿Quién es el líder de la organización? ¿De qué manera él transmite la esencia de Enseña Perú?

¿Características del líder? - Trato con los colaboradores.

¿Cómo logran que los PEP interioricen Enseña Perú?

¿De qué manera están empoderando a los PEP para que ellos sean líderes de este movimiento? ¿Cómo los motivan a seguir y que se comprometan?

¿Existen reconocimientos para ellos por parte de ustedes? ¿Cuáles son?

Enseña Perú tiene una visión muy grande. ¿Cómo hacen para cada año acercarse a la meta? ¿Cómo están los resultados?

Como líder de la organización y como parte de la historia de Enseña Perú, ¿cómo logra transmitir la identidad de enseña? ¿Qué es lo que le transmite para que ellos compartan con sus PEP? (pregunta para el Director).

¿En qué consisten las visitas que tienen con los PEP en las diferentes regiones? ¿Cuál es el objetivo de realizar esto? ¿Cuáles han sido los resultados?

¿Cómo han posicionado la marca? ¿Cuál es el mensaje que siempre se debe repetir en todos sus productos comunicacionales?

¿De qué manera logran que todas las gerencias engranen entre ellas? 


\section{ÍNDICE DE FIGURAS}

Figura 4.1. Grupos de colaboradores de Enseña Perú 16

Figura 4.2. Organigrama de Enseña Perú 17 


\section{INDICE DE TABLAS}

Tabla 5.1. Postulaciones de los PEP de 2012 a 2014 